NBER WORKING PAPER SERIES

HOW MANY LIFE-YEARS HAVE NEW DRUGS SAVED? A 3-WAY FIXED-EFFECTS ANALYSIS OF 66 DISEASES IN 27 COUNTRIES, 2000-2013

\author{
Frank R. Lichtenberg \\ Working Paper 25483 \\ http://www.nber.org/papers/w25483 \\ NATIONAL BUREAU OF ECONOMIC RESEARCH \\ 1050 Massachusetts Avenue \\ Cambridge, MA 02138 \\ January 2019
}

This work was supported by Asociación de Laboratorios Farmacéuticos de Investigación y Desarrollo (AFIDRO). The views expressed herein are those of the author and do not necessarily reflect the views of the National Bureau of Economic Research.

NBER working papers are circulated for discussion and comment purposes. They have not been peer-reviewed or been subject to the review by the NBER Board of Directors that accompanies official NBER publications.

(C) 2019 by Frank R. Lichtenberg. All rights reserved. Short sections of text, not to exceed two paragraphs, may be quoted without explicit permission provided that full credit, including () notice, is given to the source. 
How Many Life-Years Have New Drugs Saved? A 3-Way Fixed-Effects Analysis of 66 Diseases in 27 Countries, 2000-2013

Frank R. Lichtenberg

NBER Working Paper No. 25483

January 2019

JEL No. I1,J11,O30

\begin{abstract}
We analyze the role that the launch of new drugs has played in reducing the number of years of life lost (YLL) before 3 different ages (85, 70, and 55) due to 66 diseases in 27 countries.

We estimate 2-way fixed-effects models of the rate of decline of the disease- and country-specific age-standardized YLL rate. The models control for the average decline in the YLL rate in each country and from each disease.

One additional drug launch 0-11 years before year $\mathrm{t}$ is estimated to have reduced the pre-age-85 YLL rate (YLL85) in year t by 3.0\%, and one additional drug launch 12 or more years before year $\mathrm{t}$ is estimated to have reduced YLL85 by 5.5\%. (A drug's utilization peaks 8-10 years after it was launched.) Controlling for the number of drugs previously launched, YLL rates are unrelated to the number of drug classes previously launched.

The estimates imply that, if no new drugs had been launched after 1981, YLL85 in 2013 would have been 2.16 times as high as it actually was. We estimate that pharmaceutical expenditure per life-year saved before age 85 in 2013 by post-1981 drugs was $\$ 2837$. This amount is about $8 \%$ of per capita GDP, indicating that post-1981 drugs launched were very cost-effective, overall. But the fact that an intervention is cost-effective does not necessarily mean that it is "affordable."
\end{abstract}

Frank R. Lichtenberg

Columbia University

504 Uris Hall

3022 Broadway

New York, NY 10027

and NBER

frl1@columbia.edu 


\section{How many life-years have new drugs saved? A 3-way fixed-effects analysis of 66 diseases in 27 countries, 2000-2013 Extended abstract}

We perform an econometric analysis of the role that pharmaceutical innovation - the introduction and use of new drugs - has played in reducing the number of years of life lost (YLL) before 3 different ages $(85,70$, and 55) due to 66 diseases in 27 countries. We estimate 2way fixed-effects models of the rate of decline of the disease- and country-specific agestandardized premature mortality rate. The models control for the average (across diseases) decline in the premature mortality rate in each country, and the average (across countries) decline in the premature mortality rate from each disease. This approach is feasible because the relative number of drugs launched for different diseases has varied considerably across countries.

One additional drug launch $0-11$ years before year $t$ is estimated to have reduced the preage-85 YLL rate (YLL85) in year t by 3.0\%, and one additional drug launch 12 or more years before year $t$ is estimated to have reduced YLL85 by 5.5\%. The larger estimated effect of drugs launched 12 or more years before year $\mathrm{t}$ is not surprising, considering the gradual diffusion of new drugs and the likelihood of a lag from utilization to mortality reduction. When lower YLL age thresholds are used, the estimates are qualitatively similar to, but larger in magnitude than, the YLL85 estimates. Controlling for the number of drugs previously launched, YLL rates are unrelated to the number of drug classes previously launched.

The estimates imply that, if no new drugs had been launched after 1981, YLL85 in 2013 would have been 2.16 times as high as it actually was. For a subset of 22 countries for which complete 2013 pharmaceutical expenditure data are available, we estimate that the number of life-years before age 85 gained in 2013 from drugs launched after 1981 was 148.7 million. We also estimate that drugs launched after 1981 saved 82.6 million life years before age 70 and 44.9 million life-years before age 55 in 22 countries in 2013. The fraction of life-years saved by more recent drugs is slightly larger than their fraction of drug volume, which is consistent with the hypothesis that the average quality of new drugs is superior to the average quality of older drugs.

We estimate that pharmaceutical expenditure per life-year saved before age 85 in 2013 by post-1981 drugs was \$2837. This amount is about 8\% of per capita GDP, so these estimates indicate that the new drugs launched after 1981 were very cost-effective, overall.

Post-1981 drug launches are estimated to have reduced YLL85 by 34\% between 2000 and 2013, which is larger than the actual 2000-2013 reduction in YLL85: 23\%. Similarly, the estimated 2000-2013 reductions in YLL70 and YLL55 (39\% and 42\%, respectively) are larger than the actual (24\% and $28 \%)$ reductions. One possible explanation for the finding that the estimated drug-launch-induced YLL declines are larger than the actual declines is that trends in other factors (e.g. diabetes and obesity prevalence) were increasing mortality. Another possible explanation is that mortality-increasing between-disease spillover effects (e.g. cardiovascular drug launches might increase cancer mortality) outweigh mortality-reducing spillover effects (e.g. mental health drug launches might reduce cardiovascular mortality). But even if the number of life-years saved in 2013 was $33 \%$ or $50 \%$ lower than the amount implied by our estimates (which do not account for between-disease spillover effects), the evidence indicates that drugs launched since 1982 have been highly cost-effective, overall. But the fact that an intervention is cost-effective does not necessarily mean that it is "affordable." 


\section{Introduction}

Global health has improved during the $21^{\text {st }}$ century. Life expectancy at birth increased from 66.5 years in 2000 to 72.0 years in 2016 [1]. Also, according to the WHO's Global Health Estimates, the number of years of life $\operatorname{lost}^{1}$ per 100,000 population declined by $29 \%$ between 2000 and 2016 [2]. Longevity has increased, despite the fact that the global prevalence (agestandardized) of diabetes has nearly doubled since 1980 , rising from $4.7 \%$ to $8.5 \%$ in the adult population [3], and the global prevalence of obesity (BMI $\geq 30$ ) among adults increased 39\% (from $8.7 \%$ to $12.1 \%$ of the population) between 2000 and 2013 [4].

Some researchers have argued that biomedical innovation has been the principal cause of recent improvements in health. Fuchs [5] said that "since World War II...biomedical innovations (new drugs, devices, and procedures) have been the primary source of increases in longevity," although he did not provide evidence to support this claim. Cutler, Deaton and Lleras-Muney [6] performed a survey of a large and diverse literature on the determinants of mortality, and "tentatively identif[ied] the application of scientific advance and technical progress (some of which is induced by income and facilitated by education) as the ultimate determinant of health." They concluded that "knowledge, science, and technology are the keys to any coherent explanation" of mortality. Other research has shown that most technological progress is "embodied": to benefit from technological progress, people must use new products and services. $^{2}$

Most scholars agree with Jones' [9] statement that "technological progress is driven by research and development (R\&D) in the advanced world" (pp. 89-90). In 1997, the medical substances and devices sector was the most R\&D-intensive ${ }^{3}$ major industrial sector in the U.S.: almost twice as R\&D-intensive as the next-highest sector (information and electronics), and three times as R\&D-intensive as the average for all major sectors. [10]. According to Dorsey et

\footnotetext{
${ }^{1}$ Years of life lost (YLL) is an estimate of the average years a person would have lived if he or she had not died prematurely. It is, therefore, a measure of premature mortality. One can calculate the number of years of life lost before different ages. If a person died at age 60 , he or she lost 10 years before age 70 and 25 years before age 85 . ${ }^{2}$ Solow [7] argued that "many if not most innovations need to be embodied in new kinds of durable equipment before they can be made effective. Improvements in technology affect output only to the extent that they are carried into practice either by net capital formation or by the replacement of old-fashioned equipment by the latest models..." Hercowitz [8] concluded that "'embodiment' is the main transmission mechanism of technological progress to economic growth" (p. 223).

${ }^{3} R \& D$ intensity is the ratio of $R \& D$ to sales.
} 
al [11], in 2008, $88 \%$ of privately-funded U.S. biomedical research expenditure was funded by pharmaceutical and biotechnology firms; the remaining $11 \%$ was funded by medical device firms.

The purpose of this study is to assess econometrically the role that pharmaceutical innovation - the introduction and use of new drugs - has played in reducing the number of years of life lost before 3 different ages (age 85, 70, and 55) in 27 countries. During the period 1982$2015,{ }^{4} 1300$ new chemical entities (NCEs) ${ }^{5}$ were launched ${ }^{6}$ in one or more of those countries. For reasons discussed below, there is likely to be a substantial lag between the launch of a new drug and its maximum impact on the burden of disease, so we will allow for considerable lags in the relationship between new drug launches and the burden of disease.

Figure 1 shows the number of NCE launches during 1982-2015, by country. The number of NCE launches in the two countries with the smallest number of launches (Israel and Venezuela) was about half as large as the number of NCE launches in the two countries with the highest number of launches (the USA and Germany). The number of new drug launches also varied considerably across diseases. Figure 2 shows the number of new chemical substances used to treat 30 diseases that were launched in at least one country during 1982-2015.

We have ("three-dimensional") data on both the number of drug launches and the agestandardized premature mortality rate by country, disease, and year, so our analysis will be based on a three-way fixed effects model of the premature mortality rate. From that model, we will derive a 2-way fixed-effects model (which is easier to estimate) of the rate of decline of the premature mortality rate. That model will include both country fixed effects, which control for the average (across diseases) decline in the premature mortality rate in each country, and disease fixed effects, which control for the average (across countries) decline in the premature mortality rate from each disease. This approach is feasible because the relative number of drugs launched for different diseases has varied considerably across countries. This is illustrated by Figure 3, which shows the number of drugs launched during 2006-2015 in Japan and Portugal for 19 types of cancer. The mean (across cancer sites) number of drugs launched during 2006-2015 was

\footnotetext{
${ }^{4}$ Our drug launch data cover the period January 1982-November 2015.

5 The FDA defines a new chemical entity as a drug that contains no active moiety that has been approved by the FDA in any other application submitted under section 505(b) of the Federal Food, Drug, and Cosmetic Act.

${ }^{6}$ The launch of a drug is defined as the first commercial sale of the drug.
} 
almost identical in Japan and Portugal (3.3 and 3.2, respectively), but Japan launched 4 more drugs for leukemia and 4 fewer drugs for ovary cancer.

Different organizations use different age thresholds to compute YLL. The age threshold used in the OECD Health Statistics database [12] is age 70. A U.S. Centers for Disease Control and Prevention website [13] allows one to calculate YLL before ages 65, 70, 75, 80, and 85. The Global Burden of Disease 2010 reference life table used an age threshold of 86 years. WHO Global Health Estimates uses an age threshold of 91.93 years. $^{7}$ We will analyze the agestandardized rate of years of life lost before three ages $(85,70$, and 55$)$.

In the next section, we will describe the econometric model that we will use to assess the role that pharmaceutical innovation has played in reducing premature mortality from 66 diseases in 28 countries during the period 2000-2013. The data sources used to estimate this model are discussed on Section III. Empirical results are presented in Section IV. Some implications of the estimates are discussed on Section V. Section VI provides a summary.

\section{Methods}

The first models we will use to assess the impact that pharmaceutical innovation had on premature mortality will be based on the following 3-way fixed effects equation:

$$
\ln \left(\mathrm{Y}_{\mathrm{dct}}\right)=\beta_{0-11} \text { LAUNCHES_0_11 } 1_{\mathrm{dct}}+\beta_{12+} \text { LAUNCHES_GE_12 } 12_{\mathrm{dct}}+\alpha_{\mathrm{dc}}+\delta_{\mathrm{dt}}+\gamma_{\mathrm{ct}}+\varepsilon_{\mathrm{dct}}
$$

where $\mathrm{Y}_{\mathrm{dct}}$ is one of the following variables:

$$
\begin{aligned}
& \text { YLL85 }_{\mathrm{dct}}=\text { the age-standardized rate of years of life lost before age } 85 \text { per } \\
& 100,000 \text { population below age } 85 \text { due to disease } d \text { in country c in year } t \\
& (\mathrm{t}=2000,2013) \\
& \text { YLL70 }_{\mathrm{dct}}=\text { the age-standardized rate of years of life lost before age } 70 \text { per } \\
& 100,000 \text { population below age } 70 \text { due to disease } d \text { in country } \mathrm{c} \text { in year } \mathrm{t}
\end{aligned}
$$

\footnotetext{
${ }^{7}$ Some of the experts consulted by WHO argued that it was not appropriate to set the normative loss of years of life in terms of currently observed death rates, since even for the lowest observed death rates there are a proportion of deaths that are preventable or avertable. In fact, Japanese females have already exceeded the GBD 2010 reference life expectancy at birth, with a life expectancy at birth in 2013 of 87.1 years. Since the loss function is intended to represent the maximum life span of an individual in good health, who is not exposed to avoidable health risks, or severe injuries, and receives appropriate health services, the WHO chose to base its Global Health Estimates YLL age threshold on the frontier national life expectancy projected for the year 2050 by the World Population Prospects 2012. The highest projected life expectancies for the year 2050 are projected to be achieved by women in Japan and the Republic of Korea, with a life expectancy at birth of 91.9 years. While this may still not represent the ultimate achievable human life spans, it does represent a set of life spans which are thought likely to be achieved by a substantial number of people who are alive today [14]. See World Health Organization [15].
} 
YLL55 $_{\mathrm{dct}}=$ the age-standardized rate of years of life lost before age 55 per 100,000 population below age 55 due to disease $\mathrm{d}$ in country $\mathrm{c}$ in year $\mathrm{t}$

and

LAUNCHES_0_11 dct $=$ the number of new drugs to treat disease $d$ that were launched in country c 11 or fewer years before year $t$

LAUNCHES_GE_12 dct $=$ the number of new drugs to treat disease $d$ that were launched in country c more than 11 years before year $\mathrm{t}$

$$
\begin{aligned}
& \alpha_{\mathrm{dc}}=\mathrm{a} \text { fixed effect for disease } \mathrm{d} \text { in country } \mathrm{c} \\
& \delta_{\mathrm{dt}}=\mathrm{a} \text { fixed effect for disease } \mathrm{d} \text { in year } \mathrm{t} \\
& \gamma_{\mathrm{ct}}=\mathrm{a} \text { fixed effect for country } \mathrm{c} \text { in year } \mathrm{t}
\end{aligned}
$$

Eq. (1) may be considered a health production function [16], and the number of new drugs launched may be considered a measure of the stock of pharmaceutical "ideas." Jones [17] argued that "long-run growth is driven by the discovery of new ideas throughout the world." 8 Nordhaus [18] argued that "improvements in health status have been a major contributor to economic welfare over the twentieth century. To a first approximation, the economic value of increases in longevity in the last hundred years is about as large as the value of measured growth in non-health goods and services." The specification of eq. (1) incorporates the assumption of diminishing marginal productivity of drug launches: each additional drug launch for a disease results in a diminishing absolute reduction in mortality.

Estimates based on eq. (1) will provide evidence about the impact of the launch of drugs for a disease on the burden of that disease, but they will not capture possible spillover effects of the drugs on the burden of other diseases. These spillovers may be either positive or negative. For example, the launch of cardiovascular drugs could reduce mortality from cardiovascular disease, but increase mortality from the "competing risk" of cancer. On the other hand, the launch of drugs for mental disorders could reduce mortality from other medical conditions. Prince et al [19] argued that "mental disorders increase risk for communicable and non-

\footnotetext{
${ }^{8}$ The discovery of new ideas could increase economic output for two different reasons. First, output could simply be positively related to the quantity (and variety) of ideas ever discovered. Second, output could be positively related to the (mean or maximum) quality of ideas ever discovered, and new ideas may be better (of higher quality), on average, than old ideas.
} 
communicable diseases, and contribute to unintentional and intentional injury. Conversely, many health conditions increase the risk for mental disorder, and comorbidity complicates helpseeking, diagnosis, and treatment, and influences prognosis."

The launch of a drug in a country indicates that patients could have been treated with that drug, not necessarily that patients were treated with that drug. We would prefer to estimate models in which the explanatory variables measured the drugs actually used to treat patients, by disease, country, and year. We have annual data for 2007-2017 on the utilization of each drug in each country. However, many drugs have multiple indications - $50 \%$ of drugs have 2 or more indications (causes of disease in the WHO Global Health Estimates disease classification), and $7 \%$ of drugs have 5 or more indications - and our data do not enable us to determine how often each drug was used for each of its indications.

Since our drug launch variables are imperfect measures of exposure to pharmaceutical innovation, the estimated coefficients on those variables are likely to be biased towards zero, and our estimates of the number of life-years saved by new drugs are likely to be conservative. Here is the first paragraph of the eminent MIT econometrician Jerry Hausman's article on mismeasured variables in econometric analysis [20, p. 57]:

The effect of mismeasured variables in statistical and econometric analysis is one of the oldest known problems, dating from the 1870s in Adcock (1878). In the most straightforward regression analysis with a single regressor variable, the least squares estimate is downward biased in magnitude toward zero. While a mismeasured right-hand side variable creates this problem, a mismeasured left-hand side variable under classical assumptions does not lead to bias. The only result is less precision in the estimated coefficient and a lower t-statistic.

Models based on eq. (1) will be estimated using data on 66 diseases in 27 countries in 2000 and 2013. ${ }^{9}$ We will also estimate models based on more general versions of eq. (1) that will allow either (1) the effect of drugs launched 0-5 years before year $t$ to differ from the effect of drugs launched 6-11 years before year t, and (2) mortality to depend on the number of new classes of drugs launched in addition to the number of new drugs launched.

In eq. (1), drugs launched in two periods (11 or fewer years before year $\mathrm{t}$ vs. more than 11 years before year $t$ ) are allowed to have different effects on mortality in year $t$. We will perform tests of the null hypothesis $\beta_{0-11}=\beta_{12+}$, but we expect $\left|\beta_{0-11}\right|<\mid \beta_{12+}$, i.e. we expect drugs

\footnotetext{
${ }^{9}$ Data on drug launches or (in a few cases) on YLL rates were not available for other countries.
} 
launched more than 11 years before year $t$ to have a more negative impact on mortality in year $t$ than drugs launched 11 or fewer years before year $t$. There is likely to be a substantial lag between the launch of a new drug and its maximum impact on the burden of disease. Utilization of recently-launched drugs tends to be much lower than utilization of drugs launched many years earlier. Evidence about the shape of the drug-age (number of years since launch) drug-utilization profile can be obtained by estimating the following equation:

$$
\ln \left(\mathrm{N}_{-} \mathrm{SU}_{\mathrm{mcn}}\right)=\rho_{\mathrm{mc}}+\pi_{\mathrm{n}}+\varepsilon_{\mathrm{mcn}}
$$

where

$$
\begin{aligned}
\mathrm{N}_{-} S U_{\mathrm{mcn}} & =\text { the number of standard units of molecule } \mathrm{m} \text { sold in country } \mathrm{c} \mathrm{n} \\
& \text { years after it was first launched }(\mathrm{n}=0,1, \ldots, 18) \\
\rho_{\mathrm{mc}} & =\mathrm{a} \text { fixed effect for molecule } \mathrm{m} \text { in country } \mathrm{c} \\
\pi_{\mathrm{n}} & =\mathrm{a} \text { fixed effect for age } \mathrm{n}
\end{aligned}
$$

The expression $\exp \left(\pi_{n}-\pi_{8}\right)$ is a "relative utilization index": it is the mean ratio of the quantity of a drug sold in country c n years after it was launched to the quantity of the same drug sold 8 years after it was launched. We estimated eq. (2), using annual data for the period 20072017 on 721 molecules. Estimates of the "relative utilization index" are shown in Figure 4. These estimates indicate that utilization of a drug reaches a peak about 8-10 years after it was launched. It is used about twice as much then as it was two years after launch.

Due to gradual diffusion of new drugs, the maximum impact of a drug on disease burden is likely to occur a number of years after it was launched, but the peak effect could occur either more than or less than 8-10 years after launch. The lag might be longer because some drugs for chronic diseases (e.g. statins) may have to be consumed for several years to achieve full effectiveness. But the lag might be shorter because the impact of a drug on disease burden is likely to depend on its quality (or effectiveness) as well as on its quantity (utilization), and drugs launched more recently are likely to be of higher quality than earlier-vintage drugs. ${ }^{10,11}$

\footnotetext{
${ }^{10}$ Grossman and Helpman [21] argued that "innovative goods are better than older products simply because they provide more "product services' in relation to their cost of production." Bresnahan and Gordon [22] stated simply that "new goods are at the heart of economic progress," and Bils [23] said that "much of economic growth occurs through growth in quality as new models of consumer goods replace older, sometimes inferior, models." As noted by Jovanovic and Yatsenko [24], in "the Spence-Dixit-Stiglitz tradition...new goods [are] of higher quality than old goods."

${ }_{11}$ The impact on mortality may depend on the interaction (quantity * quality) of the two variables. The mortality impact will increase with respect to drug age (time since launch) if the rate of increase of quantity with respect to age is greater than the rate of decline of quality with respect to age; otherwise the mortality impact will decline.
} 
In our analysis, a drug is a ( $5^{\text {th }}$-level) chemical substance (e.g. atorvastatin, ATC code C10AA05), as defined in the WHO Anatomical Therapeutic Chemical (ATC) Classification System. ${ }^{12}$ A new drug launch is the first observed launch of a $\left(5^{\text {th }}\right.$-level $)$ chemical substance corresponding to a new chemical entity (NCE), as defined by IQVIA. Our data on NCE launches are left-censored: we only have data on NCEs that were launched anywhere in the world after 1981; data on pre-1982 launches are not available. Consequently, our drug launch variables (especially LAUNCHES_GE_12) are subject to measurement error: if a drug that was first launched anywhere in the world before 1982 was first launched in one of our 27 countries after 1982, it will not, but should, be counted as a new drug launch. If this measurement error is random, it is likely to bias estimates of the drug launch coefficients (especially $\beta_{12+}$ ) towards zero.

Due to data limitations, LAUNCHES_0_11 and LAUNCHES_GE_12 are the only disease- and country-specific, time-varying regressors in eq. (1). The very large number of fixed effects in the equation ${ }^{13}$ control for many unobserved potential determinants of premature mortality, e.g. they control for the possibility that the severity of ischemic heart disease tends to be greater in Brazil than it is in the United States. The country-year fixed effects $\left(\gamma_{\mathrm{ct}}\right.$ 's) control for changes in a country's attributes (e.g. its average income, educational attainment, and health care expenditure) to the extent that they have similar effects on mortality from different diseases. $^{14}$

If the data were available, we would like to include other regressors in eq. (1), including (1) disease incidence, and (2) the number of non-pharmaceutical medical innovations (e.g. medical device innovations) for disease $d$ that had been launched in country c. However, there is

\footnotetext{
${ }^{12}$ The ATC Classification System is used for the classification of active ingredients of drugs according to the organ or system on which they act and their therapeutic, pharmacological and chemical properties [25]. This pharmaceutical coding system divides drugs into different groups according to the organ or system on which they act, their therapeutic intent or nature, and the drug's chemical characteristics. Different brands share the same code if they have the same active substance and indications. Each bottom-level ATC code stands for a pharmaceutically used substance, or a combination of substances, in a single indication (or use). This means that one drug can have more than one code, for example acetylsalicylic acid (aspirin) has A01AD05 as a drug for local oral treatment, B01AC06 as a platelet inhibitor, and N02BA01 as an analgesic and antipyretic; as well as one code can represent more than one active ingredient, for example C09BB04 is the combination of perindopril with amlodipine, two active ingredients that have their own codes (C09AA04 and C08CA01 respectively) when prescribed alone.

${ }^{13}$ There are $1782(=66 \times 27)$ fixed effects for disease $d$ in country $\mathrm{c}\left(\alpha_{\mathrm{dc}}{ }^{\prime} \mathrm{s}\right)$.

${ }^{14}$ For example, suppose that $\ln \left(\mathrm{Y}_{\mathrm{dct}}\right)$ depends on $\mathrm{EDU}_{\mathrm{ct}}\left(\right.$ where $\mathrm{EDU}_{\mathrm{ct}}=$ average educational attainment in country $\mathrm{c}$ in year $\mathrm{t})$, and that $\gamma_{\mathrm{d}}$-the marginal effect of $\mathrm{EDU}_{\mathrm{ct}}$ on $\ln \left(\mathrm{Y}_{\mathrm{dct}}\right)$ - does not vary across diseases $\left(\gamma_{\mathrm{d}}=\gamma\right.$, all $\left.\mathrm{d}\right)$. Then $\gamma_{\mathrm{d}} \mathrm{EDU}_{\mathrm{ct}}=\gamma \mathrm{EDU}_{\mathrm{ct}}$, which can be written as $\gamma_{\mathrm{ct}}$.
} 
good reason to believe that failure to control for those variables is unlikely to result in overestimation of the magnitudes of $\beta_{0-11}$ and $\beta_{12+}$; exclusion of those variables may even result in underestimation of the magnitudes of those parameters. Higher disease incidence is likely to result in both higher disease burden and a larger number of drug launches:
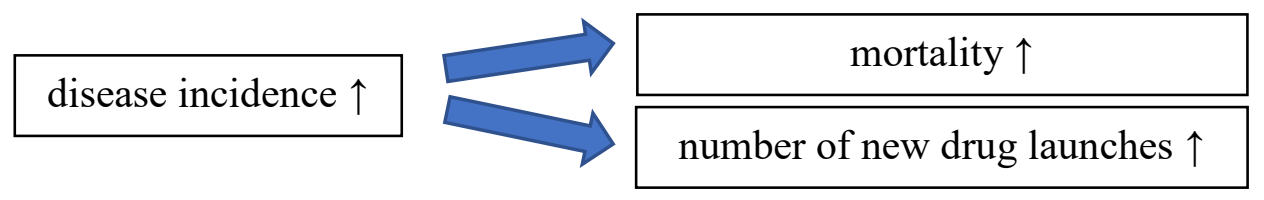

Previous studies have shown that both innovation (the number of drugs developed) and diffusion (the number of drugs launched in a country) depend on market size. Acemoglu and Linn [26] found "economically significant and relatively robust effects of market size on innovation." Danzon et al [27] found that "countries with lower expected prices or smaller expected market size experience longer delays in new drug access, controlling for per capita income and other country and firm characteristics" (emphasis added).

Although incidence data are not available for most diseases, annual incidence data for Canada during the period 1992-2010 are available for 31 cancer sites (breast, lung, etc.). As expected, there is a significant positive correlation across cancer sites between $\ln \left(\mathrm{CASES}_{\mathrm{st}}\right)$ (where CASES st $_{\text {t }}$ the number of Canadian patients diagnosed with cancer at cancer site $\mathrm{s}$ in year t) and $\ln \left(C U M \_D R U G\right.$ st $)\left(\right.$ where CUM_DRUG ${ }_{\text {st }}=$ the number of chemical substances to treat cancer at site $s$ that had ever been launched in Canada by the end of year $t$ ). But estimates of the equation $\ln \left(C U M \_D R U G_{s t}\right)=\pi \ln \left(\mathrm{CASES}_{\mathrm{st}}\right)+\alpha_{\mathrm{s}}+\delta_{\mathrm{st}}+\varepsilon_{\mathrm{st}}$ indicate that the growth rate of CUM_DRUG is uncorrelated across cancer sites with the growth rate of incidence. This suggests that estimates of $\beta_{0-11}$ and $\beta_{12+}$ in eq. (1) are unlikely to be biased by the omission of incidence in that equation.

Failure to control for non-pharmaceutical medical innovation (e.g. innovation in diagnostic imaging, surgical procedures, and medical devices) is also unlikely to bias estimates of the effect of pharmaceutical innovation on the burden of disease, for two reasons. First, as noted earlier, $88 \%$ of privately-funded U.S. funding for biomedical research came from pharmaceutical and biotechnology firms [11]. ${ }^{15}$ Second, previous research based on U.S. data

\footnotetext{
${ }^{15}$ Much of the rest came from the federal government (i.e. the NIH), and new drugs often build on upstream government research [28]. The National Cancer Institute [29] says that it "has played a vital role in cancer drug discovery and development, and, today, that role continues."
} 
$[30,31]$ indicated that non-pharmaceutical medical innovation is not positively correlated across diseases with pharmaceutical innovation.

The dependent variable of eq. (1) is the log of the level of premature mortality in year $t$. We will use data for two years: 2000 and 2013. From the 3-way fixed effects model of the log of the level of premature mortality in year t, which includes 1970 parameters, we can derive a 2way fixed effects model of the 2000-2013 growth of premature mortality, which includes only 95 parameters. Substituting the two values of $t$ into eq. (1) yields:

$$
\begin{gathered}
\ln \left(\mathrm{Y}_{\mathrm{dc}, 2000}\right)=\beta_{0-11} \text { LAUNCHES_0_1 } 11_{\mathrm{dc}, 2000}+\beta_{12+} \text { LAUNCHES_GE_1 } 2_{\mathrm{dc}, 2000} \\
+\alpha_{\mathrm{dc}}+\delta_{\mathrm{d}, 2000}+\gamma_{\mathrm{c}, 2000}+\varepsilon_{\mathrm{dc}, 2000} \\
\ln \left(\mathrm{Y}_{\mathrm{dc}, 2013}\right)=\beta_{0-11} \text { LAUNCHES_0_1 } 11_{\mathrm{dc}, 2013}+\beta_{12+} \text { LAUNCHES_GE_12 } 2_{\mathrm{dc}, 2013} \\
+\alpha_{\mathrm{dc}}+\delta_{\mathrm{d}, 2013}+\gamma_{\mathrm{c}, 2013}+\varepsilon_{\mathrm{dc}, 2013}
\end{gathered}
$$

Subtracting eq. (3) from eq. (4) yields:

$\Delta \ln \left(\mathrm{Y}_{\mathrm{dc}}\right)=\beta_{0-11} \Delta$ LAUNCHES_0_11 $1_{\mathrm{dc}}+\beta_{12+} \Delta$ LAUNCHES_GE_12 $12_{\mathrm{dc}}+\delta_{\mathrm{d}}+\gamma_{\mathrm{c}}+\varepsilon_{\mathrm{cd}}$

where

$$
\begin{aligned}
\Delta \ln \left(\mathrm{Y}_{\mathrm{dc}}\right) & =\ln \left(\mathrm{Y}_{\mathrm{dc}, 2013} / \mathrm{Y}_{\mathrm{dc}, 2000}\right) \\
\Delta \text { LAUNCHES_0_1 } 11_{\mathrm{dc}} & =\text { LAUNCHES_0_11 } 11_{\mathrm{dc}, 2013}-\text { LAUNCHES_0_1 } 11_{\mathrm{dc}, 2000} \\
\Delta \text { LAUNCHES_GE_12 } 2_{\mathrm{dc}} & =\text { LAUNCHES_GE_12 } 2_{\mathrm{dc}, 2013}-\text { LAUNCHES_GE_12 } 2_{\mathrm{dc}, 2000} \\
\delta_{\mathrm{d}} & =\delta_{\mathrm{d}, 2013}-\delta_{\mathrm{d}, 2000} \\
\gamma_{\mathrm{c}} & =\gamma_{\mathrm{c}, 2013}-\gamma_{\mathrm{c}, 2000} \\
\varepsilon_{\mathrm{dc}} & =\varepsilon_{\mathrm{dc}, 2013}-\varepsilon_{\mathrm{dc}, 2000}
\end{aligned}
$$

Eq. (5) is a 2-way fixed effects regression of the 2000-2013 growth in premature mortality from disease $\mathrm{d}$ in country c on the 2000-2013 changes in the number of drugs launched 0-11 years and more than 11 years earlier. To address the issue of heteroskedasticity, ${ }^{16}$ eq. (5) will be estimated by weighted least squares, weighting by $\left(\mathrm{POP}_{\mathrm{c}, 2000} *\left(\mathrm{Y}_{\mathrm{dc}, 2000}+\mathrm{Y}_{\mathrm{dc}, 2013}\right) / 2\right)$, where $\mathrm{POP}_{\mathrm{c}, 2000}=$ the population of country $\mathrm{c}$ in 2000 . Disturbances will be clustered within diseases.

In eqs. (1) and (5), all new drugs launched within a given period (e.g. 0-11 years before year $t$ ) are assumed to have the same effect on mortality in year $t$. It is possible that the launch of

\footnotetext{
${ }^{16}$ Growth rates of observations with low average mortality exhibit much greater variance and volatility than growth rates of observations with high average mortality.
} 
some drugs reduces mortality more than the launch of other drugs. In particular, it is possible that the launch of the first drug in a drug class, or $4^{\text {th }}$-level ATC chemical subgroup, reduces mortality more than the launch of subsequent drugs in the same $4^{\text {th }}$-level ATC chemical subgroup. ${ }^{17}$ We can assess the relative mortality impact of the launch of new drugs and the launch of new classes of drugs by generalizing eq. (5) to include two additional variables:

$$
\begin{aligned}
\Delta \ln \left(\mathrm{Y}_{\mathrm{dc}}\right)= & \beta_{0-11} \Delta \text { LAUNCHES_0_11 } 1_{\mathrm{dc}}+\beta_{12+} \Delta \text { LAUNCHES_GE_12 } 2_{\mathrm{dc}}+ \\
& \mu_{0-11} \Delta \text { CLASSES_0_1 } 11_{\mathrm{dc}}+\mu_{12+} \Delta \text { CLASSES_GE_12 } 2_{\mathrm{dc}}+\delta_{\mathrm{d}}+\gamma_{\mathrm{c}}+\varepsilon_{\mathrm{cd}}
\end{aligned}
$$

where

$\Delta$ CLASSES $0 \_11_{\mathrm{dc}}=$ the $2000-2013$ change in the number of new classes $\left(4^{\text {th }}-\right.$ level ATC chemical subgroups) of drugs to treat disease $d$ that were launched in country c 11 or fewer years earlier

$\Delta$ CLASSES_GE_12 $\mathrm{dc}=$ the $2000-2013$ change in the number of new classes of drugs to treat disease $d$ that were launched in country c 12 or more years earlier

If mortality depends only, or primarily, on the number of new chemical subgroup launches, rather than on the number of new chemical substance launches, estimates of $\mu_{0-11}$ and $\mu_{12+}$ will be statistically significant, and estimates of $\beta_{0-11}$ and $\beta_{12+}$ will be insignificant. ${ }^{18}$

\section{Data sources}

Age-standardized rates of years of life lost. Age-standardized rates of years of life lost before ages 85,70 , and 55 , by disease, country, and year, were constructed from death registration data published by the WHO [32], and from population data published by the United Nations (United Nations Population Division [33]. The disease classification used is described in Annex Table A of World Health Organization [15]. Age-standardized rates of years of life lost due to all causes before ages 85, 70, and 55 per 100,000 population, by country, are shown in Table 1 .

Drug launch data. Data on the years in which post-1981 new chemical entities were first launched in each of 28 countries were obtained from IQVIA's New Product Focus database.

\footnotetext{
${ }^{17}$ For example, the launch of lovastatin (C10AA02), the first HMG CoA reductase inhibitor (C10AA), might have reduced mortality more than the launches of the seven subsequently-launched HMG CoA reductase inhibitors.

${ }^{18}$ Due to left-censoring of the drug launch data, our data on the number of new drug classes, as well as our data on the number of new drugs, are subject to measurement error. Errors in the measurement of the number of new drug classes are likely to be greater than errors in the measurement of the number of new drugs.
} 
Drug indications data. Indications (coded by ICD-10) of chemical substances were obtained from Theriaque, a database produced by the French Centre National Hospitalier d'Information sur le Médicament [34]. ${ }^{19}$

Drug utilization and expenditure data. Data on the quantity (number of standard units) and value (in USD) of prescription drugs sold, by chemical substance, country, and year (2007-2017) were obtained from the IQVIA MIDAS database.

\section{Results}

Estimates of drug launch coefficients from nine different models of the 2000-2013 log change in the disease- and country-specific age-standardized rate of years of life lost are presented in Table 2. Models 1-3 in the table are estimates of eq. (5) for each of the three YLL age thresholds (ages 85, 70, and 55). The YLL age threshold in the first model, shown in rows 1 and 2, is age $85 .^{20}$ Estimates of the coefficients of both drug-launch regressors ( $\triangle$ LAUNCHES_0_11 and $\triangle$ LAUNCHES_GE_12) are negative and highly significant (p-value $<$ .0001). This signifies that premature (before age 85) mortality from a disease in a country is inversely related to the number of drugs for that disease that were previously launched in that country, ceteris paribus. The magnitude of the $\triangle$ LAUNCHES_GE_12 coefficient is $85 \%$ larger than the magnitude of the $\triangle$ LAUNCHES_0_11 coefficient. The chi-square statistic and its associated p-value (in the two columns on the right of the table) indicate that the null hypothesis of equality of the two coefficients is strongly rejected $(p$-value $=0.012)$. One additional drug launch $0-11$ years before year $\mathrm{t}$ is estimated to have reduced the pre-age-85 YLL rate in year $\mathrm{t}$ by $3.0 \%(=1-\exp (-0.031))$, and one additional drug launch 12 or more years before year $\mathrm{t}$ is estimated to have reduced the pre-age- 85 YLL rate by 5.5\%. The larger estimated effect of drugs launched 12 or more years before year $t$ is not surprising, considering the gradual diffusion of new drugs and the likelihood of a lag from utilization to mortality reduction.

The YLL age threshold in the second model in Table 2, shown in rows 3 and 4, is age 70. Once again, estimates of the coefficients of both drug-launch regressors are negative and highly significant ( $p$-value $<.0001)$. The null hypothesis of equality of the two coefficients is strongly

\footnotetext{
${ }^{19}$ Theriaque provides data only on labeled indications; it does not provide data on off-label indications.

${ }^{20}$ Complete estimates of this model are shown in Appendix Table 1.
} 
rejected. One additional drug launch $0-11$ years before year $\mathrm{t}$ is estimated to have reduced the pre-age-70 YLL rate in year $\mathrm{t}$ by $3.6 \%$, and one additional drug launch 12 or more years before year $t$ is estimated to have reduced the pre-age-70 YLL rate by $6.6 \%$.

The YLL age threshold in the third model in Table 2, shown in rows 5 and 6, is age 55. The estimates are qualitatively similar to, but larger in magnitude than, the pre-age- 85 and preage-70 YLL estimates. One additional drug launch 0-11 years before year $\mathrm{t}$ is estimated to have reduced the pre-age-55 YLL rate in year $\mathrm{t}$ by $4.3 \%$, and one additional drug launch 12 or more years before year $t$ is estimated to have reduced the pre-age-55 YLL rate by $7.3 \%$.

In models 4-6 of Table 2, $\triangle$ LAUNCHES_0_11 is separated into two parts: changes in the number of drug launches 0-5 years and 6-11 years before year $\mathrm{t}(\triangle \mathrm{LAUNCHES} 0$ _5 and $\triangle$ LAUNCHES_6_11, respectively). In each model, the coefficients of all three regressors are negative and significant, but the chi-square statistics indicate that the hypothesis of equality of the $\triangle$ LAUNCHES_0_5 and $\triangle$ LAUNCHES_6_11 coefficients cannot be rejected.

Models 7-9 in Table 2 are estimates, for each of the three YLL age thresholds, of the model (eq. (6)) that includes two additional variables (ACLASSES_0_11 and $\triangle$ CLASSES_GE_12) to allow us to assess the relative mortality impact of the launch of new drugs and the launch of new classes of drugs. The coefficients of both variables are insignificant in all three models: controlling for the number of drugs previously launched, YLL rates are unrelated to the number of drug classes previously launched. This finding may be interpreted in several different ways. It may signify that patients benefit from having multiple drugs within a chemical subgroup. ${ }^{21}$ Alternatively, perhaps health outcomes depend on the number of drug classes, but some drug classes are more important or valuable than others, and more valuable classes may have larger numbers of drugs. ${ }^{22}$ The insignificance of the $\triangle$ CLASSES_0_11 and $\triangle$ CLASSES_GE_12 coefficients may also be partly attributable to the fact that these variables are subject to greater measurement error than $\triangle$ LAUNCHES_0_11 and $\triangle$ LAUNCHES_GE_12.

\footnotetext{
${ }^{21}$ A later entrant in a chemical subgroup ("drug 2") may be therapeutically superior to the first-in-class drug ("drug 1 "). Even if drug 2 is not superior to drug 1, on average, it may be superior for a subset of patients.

${ }^{22}$ If the YLL rate depends on the number of drug classes previously launched, weighted by their therapeutic value, and the number of drugs in a class is indicative of the therapeutic value of the class, the YLL rate would depend on the number of drugs.
} 


\section{Discussion}

Now we will use the estimates of $\beta_{0-11}$ and $\beta_{12+}$ in models 1-3 in Table 2 to calculate several important measures: (1) the number of life-years saved (i.e., the reduction in years of life lost) before ages 85, 70, and 55 in 2013 by new drugs launched after 1981; (2) pharmaceutical expenditure per life-year saved before age 85 in 2013 by new drugs launched after 1981; and (3) the 2000-2013 decline in YLL rates attributable to new drug launches.

The first set of calculations is shown in Table 3. Calculation of the number of life-years saved before age 85 is shown in rows 1-3. The mean reduction (which we denote by $\Phi$ ) in $\ln \left(\right.$ YLL85) in 2013 attributable to drugs launched after 1981 is $\Phi=\beta_{0-11}$ * mean(LAUNCHES_0_11 $\left.11_{\mathrm{dc}, 2013}\right)+\beta_{12+} *$ mean (LAUNCHES_GE_12 $\left.\mathrm{dc}, 2013\right)$. The estimated ratio of YLL85 in the absence of new drugs to actual YLL $=1 / \exp (\Phi)$. The estimates imply that, if no new drugs had been launched after 1981, YLL85 in 2013 would have been 2.16 times as high as it actually was. Actual total YLL85 in a subset of 22 countries (listed in Table 4) for which complete 2013 pharmaceutical expenditure data are available was 128.1 million. $^{23}$ Therefore, the estimates imply that, if no new drugs had been launched after 1981, YLL85 in 2013 would have been 276.8 million, and that the number of life-years before age 85 gained in 2013 from drugs launched after 1981 was 148.7 million.

Calculations of the number of life-years saved before ages 70 and 55 are shown in rows 4-6 and 7-9, respectively, of Table 3. The estimated ratios of YLL in the absence of new drugs to actual YLL are higher (2.45 and 2.83, respectively) for the lower YLL age thresholds. We estimate that drugs launched after 1981 saved 82.6 million life years before age 70 and 44.9 million life-years before age 55 in 22 countries in 2013.

The figures in Table 3 indicate that $79 \%$ of the life-years saved before ages 85, 70, and 55 in 2013 by new drugs launched after 1981 were saved by drugs that were launched 12 or more years before (i.e. during 1982-2001). Most of those drugs probably faced generic competition: Danzon and Furukawa [35, Figure 2] showed that, in 10 countries, (unweighted) mean molecule age at generic entry was 10.2 years. Duflos and Lichtenberg [36] showed that in the US, the

\footnotetext{
${ }^{23}$ For the year 2000, the WHO Global Health Estimates figure for YLL (based on an age threshold of 91.93 years) is $63 \%$ higher than YLL85.
} 
average price of a drug 17 years after it was launched is $61 \%$ lower than the average price of the drug 12 years after it was launched.

For all three YLL age thresholds, the share of the 2013 YLL reduction attributable to drugs launched fewer than 12 years before (i.e., during 2002-2013) is 21\%. This share is slightly $(17 \%)$ higher than the ratio (18\%) of the number of standard units ("number of pills") sold in 2013 of drugs launched during 2002-2013 to the number of standard units sold in 2013 of drugs launched during 1982-2013. The fact that the fraction of life-years saved by more recent drugs is larger than their fraction of drug volume is consistent with the hypothesis discussed above that the average quality of new drugs is superior to the average quality of older drugs, especially when we consider the likelihood of a lag from drug utilization to YLL reduction.

Now we will calculate an estimate of pharmaceutical expenditure per life-year saved before age 85 in 2013 by new drugs launched after 1981. Data on pharmaceutical expenditure, by country, are shown in Table 4. The first column of figures shows 2013 expenditure on drugs launched after 1981, derived from the IQVIA MIDAS database. The second column shows 2013 expenditure on all drugs, derived from the same source. Post-1981 drugs accounted for 54\% (= $\$ 346$ b. / \$638 b.) of total drug expenditure. An estimate of total expenditure in 2014 from an alternative source [37] is $22 \%(=(\$ 778$ b. / \$638 b. $)-1)$ higher than the IQVIA estimate of total expenditure in 2013. We will use the higher (IFPMA) estimate of total expenditure, and assume that $54 \%$ of that expenditure was on post-1981 drugs, so our estimate of 2013 expenditure on post-1981 drugs was $\$ 421.8$ billion (=54\%* $\$ 778$ billion). As shown in Table 3, the number of life-years before age 85 gained in 2013 from post-1981 drugs was 148.7 million, so we estimate that pharmaceutical expenditure per life-year saved before age 85 in 2013 by post-1981 drugs was $\$ 2837$ (= $\$ 421.8$ billion / 148.7 million).

As noted by Bertram et al [38], authors writing on behalf of the WHO's Choosing Interventions that are Cost-Effective project (WHO-CHOICE) suggested in 2005 that "interventions that avert one DALY for less than average per capita income for a given country or region are considered very cost-effective; interventions that cost less than three times average per capita income per DALY averted are still considered cost-effective." 24 Weighted (by

\footnotetext{
${ }^{24}$ Other authorities use reasonably similar cost-effectiveness thresholds. The U.K. National Institute for Health and Care Excellence [39] says that, "in general, interventions with an ICER [Incremental Cost-Effectiveness Ratio] of less than $£ 20,000$ per QALY gained are considered to be cost effective." The U.S. Department of Veterans Affairs Health Economics Resource Center [40] says that "a cost-effectiveness analysis may indicate that Drug A is a good
} 
population) mean per capita GDP was $\$ 35,543$ in 2013 , so these estimates indicate that the new drugs launched after 1981 were very cost-effective, overall.

Several considerations suggest that $\$ 2837$ may be an overestimate of the true net cost in 2013 per life-year saved of post-1981 drugs. First, that estimate is based on drug cost measured at invoice price levels; rebates and discounts are not reflected. ${ }^{25}$ Second, a previous study based on U.S. data [42] showed that about $25 \%$ of the cost of new drugs is offset by reduced expenditure on old drugs. ${ }^{26}$

The last calculation we will perform will be of the 2000-2013 decline in YLL rates attributable to new drug launches. This calculation is similar to the ones in Table 3, but instead of the 2013 levels of LAUNCHES_0_11 and LAUNCHES_GE_12, we use the 2000-2013 changes in those variables. The estimated drug-launch-induced 2000-2013 log change in YLL is $\left(\beta_{0-11} *\right.$ mean $\left(\Delta\right.$ LAUNCHES_0_11) $+\beta_{12+} *$ mean $(\Delta$ LAUNCHES_GE_12) $)$. The weighted mean values of $\triangle$ LAUNCHES_0_11 and $\triangle$ LAUNCHES_GE_12 were about $-3.6^{27}$ and 9.4, respectively. Consequently, the estimated log change in YLL85 was -0.417, i.e. post-1981 drug launches are estimated to have reduced YLL85 by 34\% (= 1- exp(-0.417)) between 2000 and 2013. This is larger than the actual 2000-2013 reduction in YLL85: 23\%. Similarly, the estimated 2000-2013 reductions in YLL70 and YLL55 (39\% and 42\%, respectively) are larger than the actual (24\% and $28 \%)$ reductions.

One possible explanation for the finding that the estimated drug-launch-induced YLL declines were larger than the actual declines is that trends in other factors were increasing mortality. As noted above, the global prevalence of diabetes and obesity have increased sharply. ${ }^{28}$ Another possible explanation is that mortality-increasing between-disease spillover effects (e.g. cardiovascular drug launches might increase cancer mortality) outweigh mortalityreducing spillover effects (e.g. mental health drug launches might reduce cardiovascular mortality). But even if the number of life-years saved in 2013 was $33 \%$ or $50 \%$ lower than the

value relative to Drug B, because it has an incremental cost-effectiveness ratio (ICER) of $\$ 40,000$ per QualityAdjusted Life Year."

${ }^{25}$ In the U.S. in 2014, rebates reduced total brand name drug cost by $17.5 \%$ [41].

${ }^{26}$ That study also demonstrated that pharmaceutical innovation has reduced work-loss and school-loss days.

${ }^{27}$ There were fewer launches during 2002-2013 than there were during 1989-2000.

${ }^{28}$ However, another behavioral risk factor-smoking - has been declining. For example, smoking prevalence among men declined from $44.2 \%$ in 2000 to $36.1 \%$ in 2013.

https://data.worldbank.org/indicator/SH.PRV.SMOK.MA 
calculations in Table 3 (which do not account for between-disease spillover effects) indicate, our estimates imply that drugs launched since 1982 have been highly cost-effective, overall.

\section{Summary}

We have performed an econometric analysis of the role that pharmaceutical innovationthe introduction and use of new drugs - has played in reducing the number of years of life lost (YLL) before 3 different ages $(85,70$, and 55) due to 66 diseases in 27 countries. We used "three-dimensional" data on both the number of drug launches and the premature mortality rate by country, disease, and year, to estimate 2-way fixed-effects models of the rate of decline of the disease- and country-specific age-standardized premature mortality rate. The models controlled for the average (across diseases) decline in the premature mortality rate in each country, and the average (across countries) decline in the premature mortality rate from each disease. This approach was feasible because the relative number of drugs launched for different diseases has varied considerably across countries.

This study is subject to a number of limitations. Our measures of pharmaceutical innovation (the number of drugs and drug classes launched in a country) are imperfect. Our drug launch data are left-censored: only drugs launched anywhere in the world after 1981 are captured. Off-label use of drugs is not accounted for. Our drug indications data were obtained from a French database, and some drugs launched in other countries have not been launched in France. Our estimates provide evidence about the impact of the launch of drugs for a disease on the burden of that disease, but they do not capture possible spillover effects of the drugs on the burden of other diseases. Also, our estimates control for the effects on YLL of changes in a country's health system and macroeconomic conditions, to the extent that those effects don't vary across diseases, but those effects might vary across diseases.

Premature (before age 85) mortality from a disease in a country is inversely related to the number of drugs for that disease that were previously launched in that country, ceteris paribus. One additional drug launch $0-11$ years before year $t$ is estimated to have reduced the pre-age- 85 YLL rate (YLL85) in year $t$ by 3.0\%, and one additional drug launch 12 or more years before year $t$ is estimated to have reduced YLL85 by 5.5\%. The larger estimated effect of drugs 
launched 12 or more years before year $\mathrm{t}$ is not surprising, considering the gradual diffusion of new drugs and the likelihood of a lag from utilization to mortality reduction.

When lower YLL age thresholds are used, the estimates are qualitatively similar to, but larger in magnitude than, the YLL85 estimates. One additional drug launch 0-11 years before year $t$ is estimated to have reduced the pre-age-55 YLL rate (YLL55) in year $t$ by $4.3 \%$, and one additional drug launch 12 or more years before year $t$ is estimated to have reduced YLL55 by $7.3 \%$.

Controlling for the number of drugs previously launched, YLL rates are unrelated to the number of drug classes previously launched.

We used the estimates to calculate several important measures: (1) the number of lifeyears saved (i.e., the reduction in years of life lost) before ages 85, 70, and 55 in 2013 by new drugs launched after 1981; (2) pharmaceutical expenditure per life-year saved before age 85 in 2013 by new drugs launched after 1981; and (3) the 2000-2013 decline in YLL rates attributable to new drug launches.

The estimates implied that, if no new drugs had been launched after 1981, YLL85 in 2013 would have been 2.16 times as high as it actually was. For a subset of 22 countries for which complete 2013 pharmaceutical expenditure data are available, we estimated that the number of life-years before age 85 gained in 2013 from drugs launched after 1981 was 148.7 million. We also estimated that drugs launched after 1981 saved 82.6 million life years before age 70 and 44.9 million life-years before age 55 in 22 countries in 2013.

The fraction of life-years saved by more recent drugs is slightly larger than their fraction of drug volume, which is consistent with the hypothesis that the average quality of new drugs is superior to the average quality of older drugs.

We estimated that pharmaceutical expenditure per life-year saved before age 85 in 2013 by post-1981 drugs was $\$ 2837$. This amount is about $8 \%$ of per capita GDP, so these estimates indicate that the new drugs launched after 1981 were very cost-effective, overall.

Post-1981 drug launches were estimated to have reduced YLL85 by 34\% between 2000 and 2013, which is larger than the actual 2000-2013 reduction in YLL85: 23\%. Similarly, the estimated 2000-2013 reductions in YLL70 and YLL55 (39\% and 42\%, respectively) were larger than the actual $(24 \%$ and $28 \%)$ reductions. One possible explanation for the finding that the estimated drug-launch-induced YLL declines were larger than the actual declines is that trends in 
other factors (e.g. diabetes and obesity prevalence) were increasing mortality. Another possible explanation is that mortality-increasing between-disease spillover effects (e.g. cardiovascular drug launches might increase cancer mortality) outweigh mortality-reducing spillover effects (e.g. mental health drug launches might reduce cardiovascular mortality). But even if the number of life-years saved in 2013 was $33 \%$ or $50 \%$ lower than the amount implied by our estimates (which do not account for between-disease spillover effects), the evidence indicates that drugs launched since 1982 have been highly cost-effective, overall.

As several scholars have pointed out, the fact that an intervention is cost-effective does not necessarily mean that it is "affordable." Sendi and Briggs [43] argued that "decision-makers are constrained by a fixed-budget and may not be able to fund new, more expensive interventions, even if they have been shown to represent good value for money." In response to this limitation, those authors introduced the 'affordability curve' which reflects the probability that a program is affordable for a wide range of threshold budgets. They argued that the joint probability that an intervention is affordable and cost-effective is more useful for decisionmaking since it captures both dimensions of the decision problem faced by those responsible for health service budgets. In a similar vein, the U.S. Department of Veterans Affairs Health Economics Resource Center argues that in addition to a cost-effectiveness analysis-which evaluates whether an intervention provides value relative to an existing intervention (with value defined as cost relative to health outcome) - it may be necessary to conduct a budget impact analysis. That analysis estimates the financial consequences of adopting a new intervention, and evaluates whether the high-value intervention is affordable.

We estimated the impact on the 2013 pharmaceutical budget — $\$ 421.8$ billion—as well as the average cost-effectiveness of the drugs that were launched since 1982. Presumably, decision-makers considered those drugs to be "affordable." However, as shown in Figure 1, many potential drug launches did not occur, perhaps because decision-makers did not consider those drugs to be both cost-effective and affordable. 


\section{References}

[1] World Health Organization. Life expectancy and Healthy life expectancy, Data by WHO region, http://apps.who.int/gho/data/view.main.SDG2016LEXREGv?lang=en (25 October 2018, date last accessed)

[2] World Health Organization. Global Health Estimates, YLL estimates, Global summary estimates, http://www.who.int/healthinfo/global burden_disease/estimates/en/index1.html (25 October 2018, date last accessed)

[3] World Health Organization. Global report on diabetes, http://apps.who.int/iris/bitstream/10665/204871/1/9789241565257 eng.pdf (25 October 2018, date last accessed)

[4] World Health Organization. Obesity and overweight, http://www.who.int/news-room/factsheets/detail/obesity-and-overweight (25 October 2018, date last accessed)

[5] Fuchs, VR. New Priorities for Future Biomedical Innovations. New England Journal of Medicine 2010; 363:704-706, August 19.

[6] Cutler D, Deaton A, Lleras-Muney A. The Determinants of Mortality. Journal of Economic Perspectives 2006; 20(3): 97-120, Summer.

[7] Solow R. Investment and Technological Progress. In: Arrow K, Karlin S, Suppes P (eds). Mathematical methods in the social sciences, 1959. Stanford, CA: Stanford University Press, 1960.

[8] Hercowitz Z. The 'embodiment' controversy: A review essay. Journal of Monetary Economics 1998; 41: 217-224.

[9] Jones, CI. Introduction to Economic Growth. New York: W.W. Norton, 1998.

[10] National Science Foundation. R\&D Expenditures by Industry Category, http://wayback.archiveit.org/5902/20150819114914/http:/www.nsf.gov/statistics/nsf00301/expendit.htm\#intensity (25 October 2018, date last accessed)

[11] Dorsey ER. Financial Anatomy of Biomedical Research, 2003-2008. Journal of the American Medical Association 2010; 303(2): 137-143, January 13.

[12] OECD. OECD Health Statistics database, https://stats.oecd.org/index.aspx?DataSetCode=HEALTH_STAT (25 October 2018, date last accessed) 
[13] Centers for Disease Control and Prevention. WISQARS Years of Potential Life Lost (YPLL) Report, 1981 and 2016, https://webappa.cdc.gov/sasweb/ncipc/ypll.html (25 October 2018, date last accessed)

[14] Kontis V, Bennett JE, Mathers CD, Li G, Foreman K, Ezzati M. Future life expectancy in 35 industrialised countries: projections with a Bayesian model ensemble. Lancet 2017; 389(10076): 1323-1335, Apr 1.

[15] World Health Organization. WHO methods and data sources for global burden of disease estimates 2000-2016, http://www.who.int/healthinfo/global_burden_disease/GlobalDALY_method_2000_2016.pdf (25 October 2018, date last accessed)

[16] Koç C. The productivity of health care and health production functions. Health Economics 2004; 13(8): 739-47, August.

[17] Jones CI. Sources of U.S. Economic Growth in a World of Ideas. American Economic Review 2002; 92 (1): 220-239, March.

[18] Nordhaus WD. Irving Fisher and the Contribution of Improved Longevity to Living Standards. American Journal of Economics and Sociology 2005; 64 (1): 367-92.

[19] Prince M, Patel V, Saxena S, Maj M, Maselko J, Phillips MR, Rahman A. No health without mental health. Lancet 2007; 370 (9590): 859-77, Sep 8.

[20] Hausman J (2001). Mismeasured Variables in Econometric Analysis: Problems from the Right and Problems from the Left. Journal of Economic Perspectives 15(4): 57-67, Autumn, https://www.aeaweb.org/articles?id=10.1257/jep.15.4.57

[21] Grossman GM, Helpman E. Innovation and Growth in the Global Economy. Cambridge: MIT Press, 1993.

[22] Bresnahan TF, Gordon RJ. The Economics of New Goods. Chicago: University of Chicago Press, 1996.

[23] Bils M. "Measuring the Growth from Better and Better Goods," NBER working paper no. 10606, July, https://www.nber.org/papers/w10606 (25 October 2018, date last accessed)

[24] Jovanovic B, Yatsenko Y. Investment in Vintage Capital. Journal of Economic Theory 2012; 147(2): 551-569.

[25] WHO Collaborating Centre for Drug Statistics Methodology. ATC classification system structure and principles, https://www.whocc.no/atc/structure and principles/ (25 October 2018, date last accessed) 
[26] Acemoglu D, Linn J. Market size in innovation: theory and evidence from the pharmaceutical industry. Quarterly Journal of Economics 2004, August.

[27] Danzon PM, Wang YR, Wang L. The impact of price regulation on the launch delay of new drugs - evidence from twenty-five major markets in the 1990s. Health Economics 2005; 14(3): 269-92, March.

[28] Sampat B, Lichtenberg FR. "What are the Respective Roles of the Public and Private Sectors in Pharmaceutical Innovation?," Health Affairs 2011; 30(2):332-9, Feb. (25 October 2018, date last accessed)

[29] National Cancer Institute. Enhancing Drug Discovery and Development, https://www.cancer.gov/research/areas/treatment/enhancing-drug-discovery (25 October 2018, date last accessed)

[30] Lichtenberg FR. Has Medical Innovation Reduced Cancer Mortality? CESifo Economic Studies 2014; 60 (1): 135-177 (25 October 2018, date last accessed)

[31] Lichtenberg FR. The impact of pharmaceutical innovation on longevity and medical expenditure in France, 2000-2009. Economics and Human Biology 2014; 13: 107-127, March (25 October 2018, date last accessed)

[32] World Health Organization. Disease burden and mortality estimates: death registration data, http://www.who.int/healthinfo/global_burden_disease/GHE2016_Input-Data.7z

[33] United Nations Population Division. World Population Prospects 2017, Annual Population by Five-Year Age Groups - Both Sexes (25 October 2018, date last accessed)

[34] Centre National Hospitalier d'Information sur le Médicament. Thériaque database. http://www.theriaque.org/apps/contenu/accueil.php (25 October 2018, date last accessed)

[35] Danzon PM, Furukawa MF (2011). Cross-National Evidence on Generic Pharmaceuticals: Pharmacy vs. Physician-Driven Markets. NBER Working Paper 17226, http://www.nber.org/papers/w17226

[36] Duflos G, Lichtenberg FR (2012). Does competition stimulate drug utilization? The impact of changes in market structure on US drug prices, marketing and utilization. International Review of Law and Economics 32: 95- 109.

[37] International Federation of Pharmaceutical Manufacturers \& Associations (2017). The Pharmaceutical Industry and Global Health: Facts And Figures 2017, February, https://www.ifpma.org/wp-content/uploads/2017/02/IFPMA-Facts-And-Figures-2017.pdf (25

October 2018, date last accessed) 
[38] Bertram MY, Lauer JA, De Joncheere K, Edejer T, Hutubessy R, Kieny MP, Hill SR (2016). Cost-effectiveness thresholds: pros and cons. Bulletin of the World Health Organization. 94(12): 925-30, Dec 1.

[39] National Institute for Health and Care Excellence (2018). The Guidelines Manual: Assessing cost effectiveness, https://www.nice.org.uk/process/pmg6/chapter/assessing-costeffectiveness (29 November 2018, date last accessed)

[40] U.S. Department of Veterans Affairs, Health Economics Resource Center (2018). Budget Impact Analysis, https://www.herc.research.va.gov/include/page.asp?id=budget-impact-analysis, (29 November 2018, date last accessed)

[41] Centers for Medicare \& Medicaid Services. 2014 Part D Rebate Summary for All Brand Name Drugs, https://www.cms.gov/Research-Statistics-Data-and-Systems/Statistics-Trends-andReports/Information-on-Prescription-Drugs/PartD Rebates.html (25 October 2018, date last accessed)

[42] Lichtenberg FR. The impact of pharmaceutical innovation on disability days and the use of medical services in the United States, 1997-2010. Journal of Human Capital 2014; 8(4): 432-80, Winter.

[43] Sendi PP, Briggs AH (2001). Affordability and cost-effectiveness: decision-making on the cost-effectiveness plane. Health Economics 10(7): 675-80, October. 
Figure 1

Number of post-1981 New Chemical Entity launches, 1982-2015, by country

100

200

300

400

500

600

700

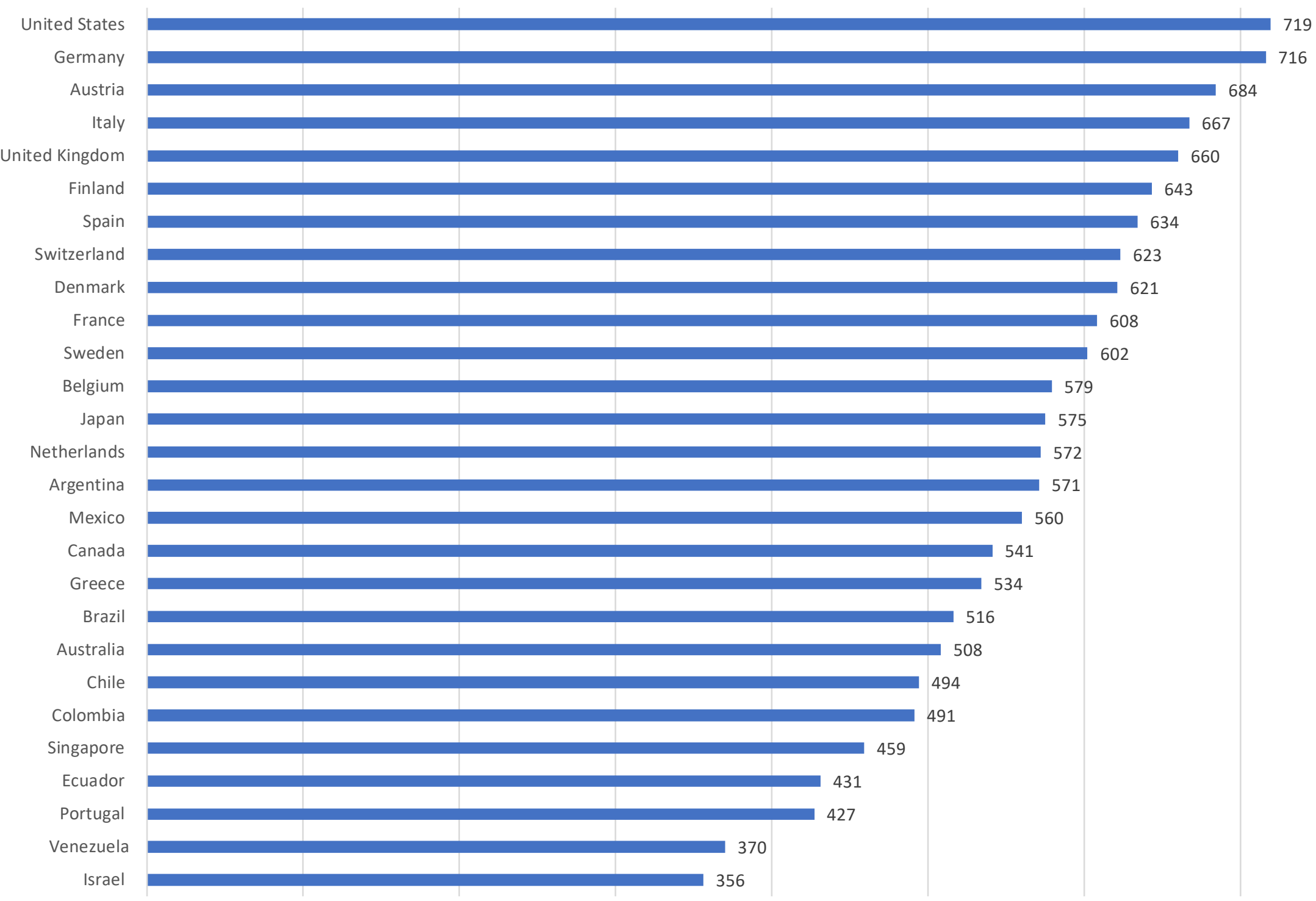


Figure 2

Number of new 5th-level ATC codes, by selected medical condition

0

10

15

20

25

30

35

1120 Hypertensive heart disease

390 Lower respiratory infections

800 Diabetes mellitus

100 HIV/AIDS

1130 Ischaemic heart disease

1270 Kidney disease

700 Breast cance

770 Leukaemia

1350 Rheumatoid arthritis

1180 Chronic obstructive pulmonary disease

762 Non-Hodgkin lymphoma

400 Upper respiratory infections

680 Trachea, bronchus, lung cancers

830 Depressive disorder

970 Epilepsy

980 Multiple sclerosis

740 Prostate cancer

1380 Back and neck pain

1030 Glaucoma

1360 Osteoarthritis

650 Colon and rectum cancers

691 Malignant skin melanoma

880 Anxiety disorders

960 Parkinson disease

1140 Stroke

1190 Asthma

170 Meningitis

670 Pancreas cancer

1220 Peptic ulcer disease

1280 Benign prostatic hyperplasia

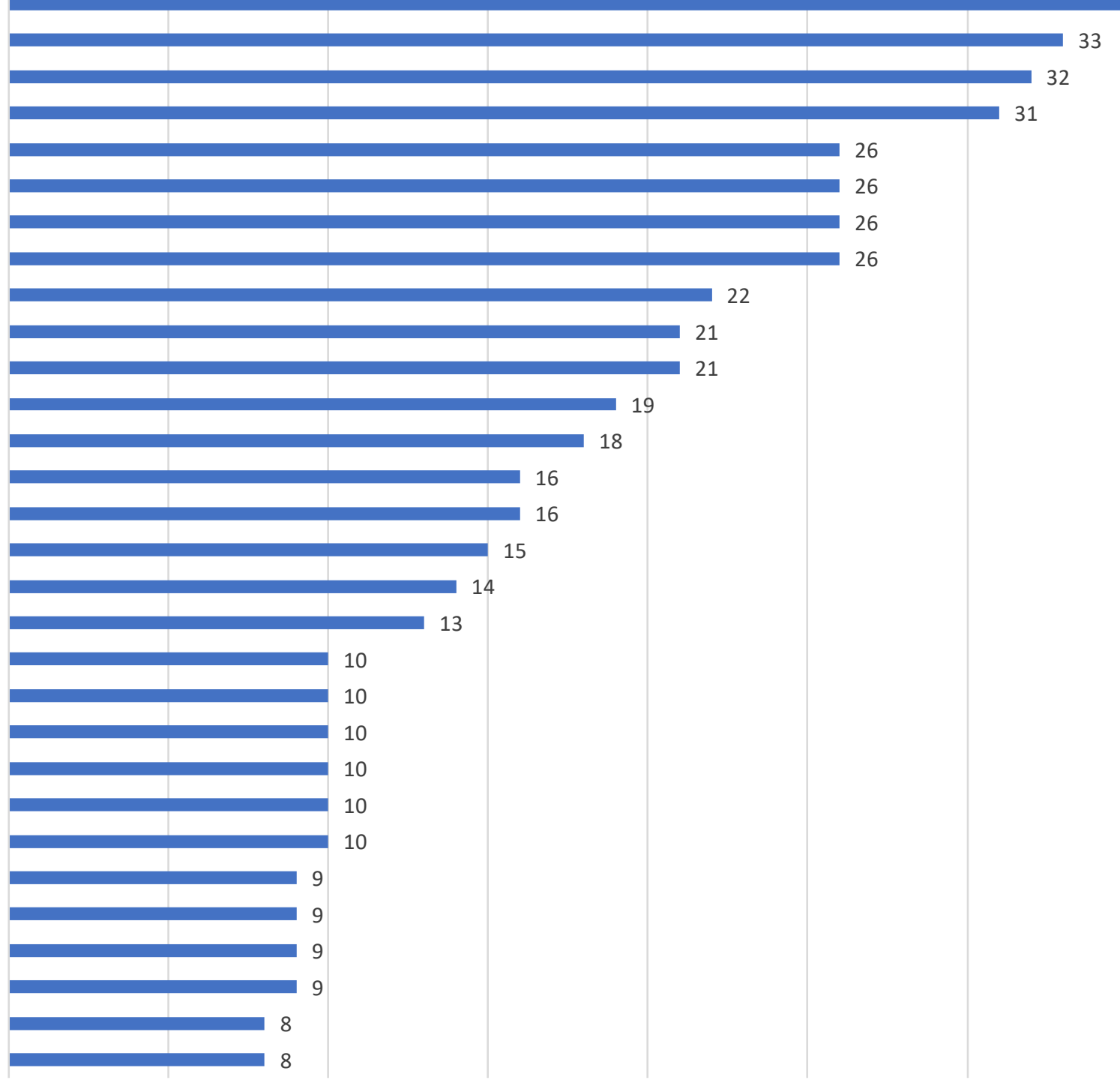


Figure 3

Number of drugs launched during 2006-2015 in Japan and Portugal for 19 types of cancer

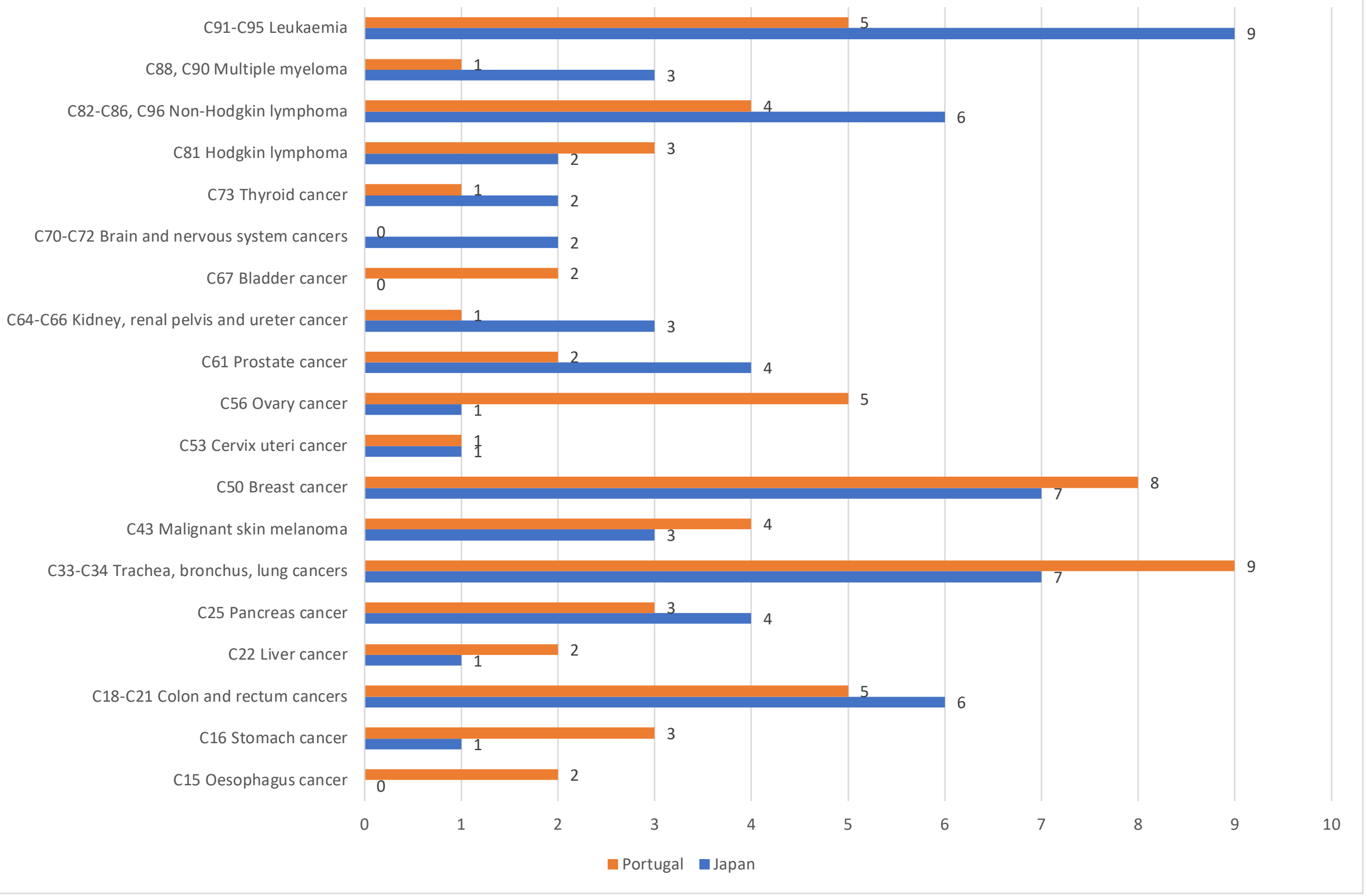


Figure 4

Estimates of relative drug utilization, by number of years since launch

1.2

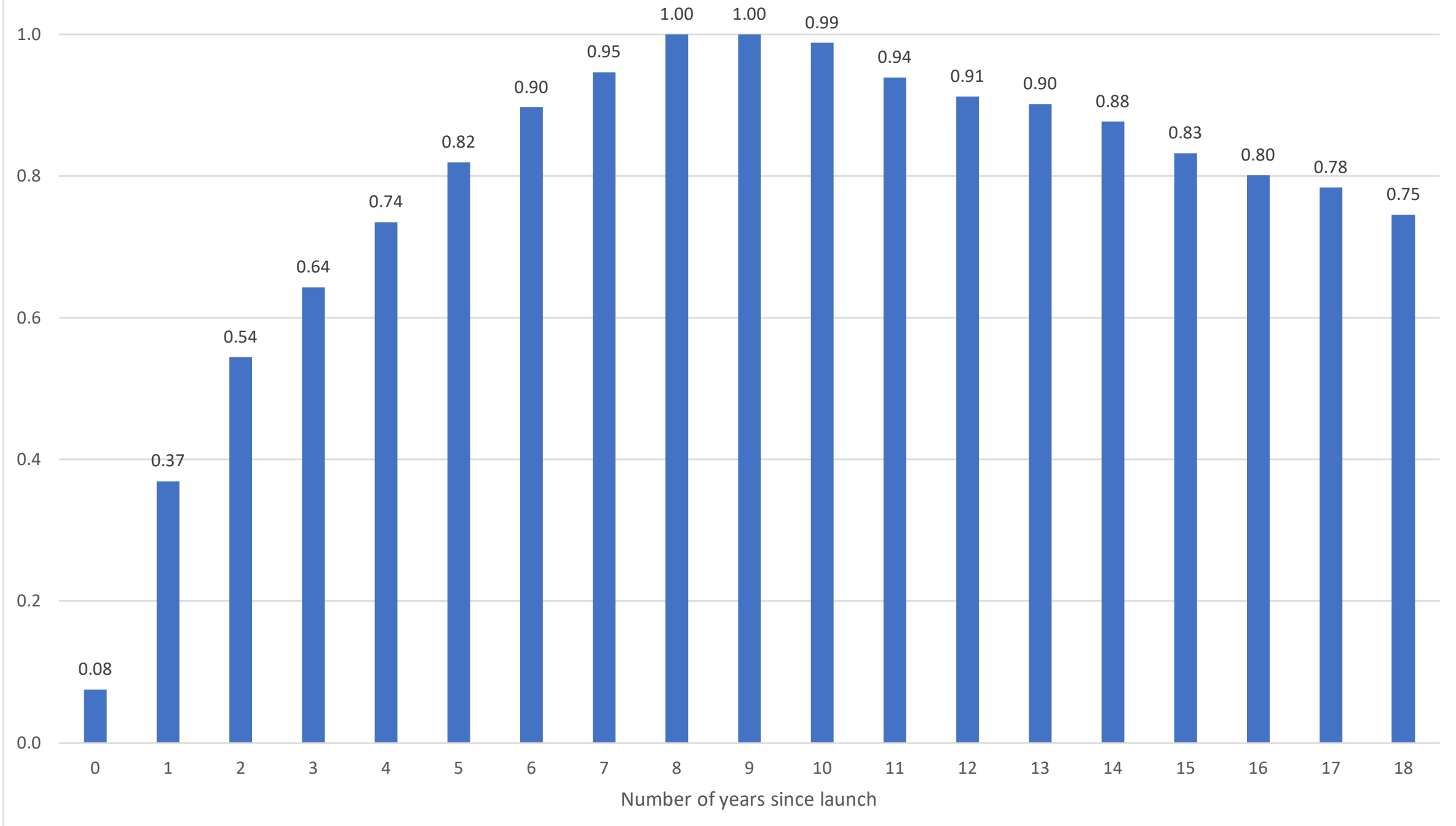




\section{Table 1}

Age-standardized rates of years of life lost due to all causes before ages 85,70 , and 55 per 100,000 population, by country

\begin{tabular}{|c|c|c|c|c|c|c|c|}
\hline \multirow[b]{2}{*}{ country } & \multicolumn{2}{|c|}{ YLL85 } & \multicolumn{2}{|c|}{ yll70 } & \multicolumn{2}{|c|}{ YLL55 } & \multirow{2}{*}{$\frac{\text { population (000s) }}{2000}$} \\
\hline & 2000 & 2013 & 2000 & 2013 & 2000 & 2013 & \\
\hline Argentina & 14,155 & 11,867 & 7,679 & 6,185 & 4,572 & 3,553 & 37,047 \\
\hline Australia & 8,667 & 6,297 & 3,961 & 2,858 & 2,045 & 1,393 & 19,057 \\
\hline Austria & 10,722 & 7,851 & 4,421 & 3,080 & 1,958 & 1,247 & 8,060 \\
\hline Belgium & 11,710 & 8,957 & 4,805 & 3,509 & 2,216 & 1,462 & 10,273 \\
\hline Brazil & 15,163 & 12,496 & 9,360 & 7,711 & 5,784 & 4,730 & 175,279 \\
\hline Canada & 9,048 & 7,159 & 3,921 & 3,222 & 1,825 & 1,539 & 30,728 \\
\hline Chile & 9,833 & 7,931 & 5,202 & 4,171 & 2,900 & 2,298 & 15,256 \\
\hline Colombia & 14,796 & 9,111 & 9,789 & 5,818 & 6,482 & 3,790 & 40,394 \\
\hline Denmark & 12,213 & 8,417 & 4,799 & 3,219 & 1,948 & 1,197 & 5,332 \\
\hline Ecuador & 14,145 & 9,080 & 9,593 & 5,924 & 6,552 & 3,907 & 12,620 \\
\hline Spain & 9,939 & 6,643 & 4,119 & 2,539 & 1,971 & 1,028 & 40,894 \\
\hline Finland & 11,673 & 8,517 & 4,974 & 3,498 & 2,127 & 1,398 & 5,180 \\
\hline France & 10,474 & 7,819 & 4,668 & 3,388 & 2,166 & 1,449 & 59,600 \\
\hline Germany & 11,742 & 9,015 & 4,586 & 3,390 & 1,904 & 1,271 & 81,480 \\
\hline Greece & 10,463 & 8,049 & 4,037 & 3,091 & 1,895 & 1,306 & 11,131 \\
\hline Israel & 8,571 & 5,623 & 4,057 & 2,563 & 2,239 & 1,319 & 6,004 \\
\hline Italy & 10,114 & 7,253 & 3,831 & 2,709 & 1,721 & 1,164 & 57,285 \\
\hline Japan & 8,939 & 6,911 & 3,559 & 2,718 & 1,471 & 1,093 & 127,525 \\
\hline Mexico & 12,138 & 10,647 & 7,719 & 6,596 & 4,931 & 4,145 & 101,711 \\
\hline Netherlands & 10,165 & 7,149 & 4,094 & 2,823 & 1,808 & 1,169 & 15,916 \\
\hline Portugal & 12,996 & 8,421 & 5,699 & 3,401 & 2,917 & 1,403 & 10,346 \\
\hline Singapore & 6,368 & 3,585 & 2,858 & 1,586 & 1,264 & 679 & 3,907 \\
\hline Sweden & 9,277 & 7,270 & 3,422 & 2,691 & 1,402 & 1,132 & 8,872 \\
\hline Switzerland & 9,110 & 6,357 & 3,858 & 2,571 & 1,794 & 1,133 & 7,159 \\
\hline United Kingdom & 11,137 & 8,076 & 4,316 & 3,240 & 1,929 & 1,434 & 58,943 \\
\hline United States & 11,838 & 10,151 & 5,624 & 4,943 & 2,783 & 2,408 & 281,973 \\
\hline Venezuela & 14,063 & 13,509 & 9,250 & 8,982 & 6,097 & 5,893 & 24,482 \\
\hline
\end{tabular}


Table 2

Estimates of models of the 2000-2013 log change in the disease- and country-specific age-standardized rate of years of life lost (YLL) before ages 85,70 , and 55

\begin{tabular}{|c|c|c|c|c|c|c|c|c|c|}
\hline row & model & YLL age & Regressor & Estimate & Std. Error. & $\mathbf{Z}$ & $\operatorname{Pr}>|Z|$ & $\begin{array}{c}\text { Chi- } \\
\text { Square }\end{array}$ & $\begin{array}{c}\mathrm{Pr}> \\
\text { ChiSq }\end{array}$ \\
\hline 1 & \multirow{2}{*}{1} & \multirow{2}{*}{85} & 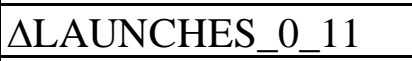 & -0.031 & 0.008 & -3.79 & 0.000 & \multirow{2}{*}{6.27} & \multirow{2}{*}{0.012} \\
\hline 2 & & & DLAUNCHES_GE_12 & -0.057 & 0.013 & -4.46 & $<.0001$ & & \\
\hline 3 & \multirow{2}{*}{2} & \multirow{2}{*}{70} & ALAUNCHES_0_11 & -0.036 & 0.011 & -3.18 & 0.002 & \multirow{2}{*}{9.00} & \multirow{2}{*}{0.003} \\
\hline 4 & & & ALAUNCHES_GE_12 & -0.068 & 0.018 & -3.76 & 0.000 & & \\
\hline & \multirow{3}{*}{3} & & & & & & & \multirow{3}{*}{6.52} & \\
\hline 5 & & \multirow{2}{*}{55} & 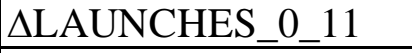 & -0.044 & 0.016 & -2.79 & 0.005 & & \multirow{2}{*}{0.011} \\
\hline 6 & & & $\Delta$ LAUNCHES_GE_12 & -0.076 & 0.026 & -2.93 & 0.003 & & \\
\hline & & & & & & & & & \\
\hline 7 & \multirow{3}{*}{4} & \multirow{3}{*}{85} & 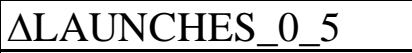 & -0.035 & 0.009 & -3.93 & $<.0001$ & \multirow{2}{*}{1.27} & \multirow{2}{*}{0.260} \\
\hline 8 & & & ALAUNCHES_6_11 & -0.023 & 0.011 & -2.15 & 0.031 & & \\
\hline 9 & & & ALAUNCHES_GE_12 & -0.055 & 0.013 & -4.06 & $<.0001$ & & \\
\hline & & & & & & & & & \\
\hline 10 & \multirow{3}{*}{5} & \multirow{3}{*}{70} & 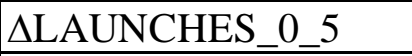 & -0.040 & 0.014 & -2.95 & 0.003 & \multirow{2}{*}{0.58} & \multirow{2}{*}{0.447} \\
\hline 11 & & & ALAUNCHES_6_11 & -0.030 & 0.012 & -2.45 & 0.014 & & \\
\hline 12 & & & ALAUNCHES_GE_12 & -0.066 & 0.018 & -3.71 & 0.000 & & \\
\hline 13 & \multirow{3}{*}{6} & \multirow{3}{*}{55} & $\triangle \mathrm{LAUNCHES} 05$ & -0.046 & 0.020 & -234 & 0.019 & \multirow{2}{*}{0.15} & \multirow[b]{2}{*}{0.701} \\
\hline 14 & & & $\triangle \mathrm{LAUNCHES} 611$ & -0.040 & 0.013 & -3.22 & 0.001 & & \\
\hline 15 & & & DLAUNCHES_GE_12 & -0.075 & 0.025 & -3.05 & 0.002 & & \\
\hline & & & & & & & & & \\
\hline 16 & \multirow{4}{*}{7} & \multirow{4}{*}{85} & 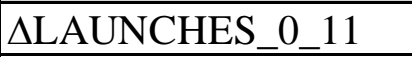 & -0.032 & 0.015 & -2.23 & 0.025 & & \\
\hline 17 & & & $\Delta$ LAUNCHES_GE_12 & -0.060 & 0.021 & -2.91 & 0.004 & & \\
\hline 18 & & & $\Delta$ CLASSES_0_11 & 0.005 & 0.021 & 0.23 & 0.816 & & \\
\hline 19 & & & $\Delta$ CLASSES_GE_12 & 0.009 & 0.030 & 0.31 & 0.760 & & \\
\hline 20 & \multirow{4}{*}{8} & \multirow{4}{*}{70} & 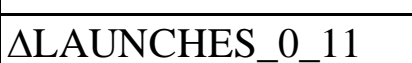 & -0.043 & 0.018 & -2.37 & 0.018 & & \\
\hline 21 & & & ALAUNCHES_GE_12 & -0.082 & 0.027 & -3.10 & 0.002 & & \\
\hline 22 & & & $\Delta$ CLASSES_0_11 & 0.020 & 0.024 & 0.84 & 0.399 & & \\
\hline 23 & & & $\Delta$ CLASSES_GE_12 & 0.040 & 0.038 & 1.04 & 0.297 & & \\
\hline & & & & & & & & & \\
\hline 24 & & & 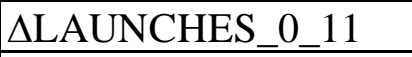 & -0.056 & 0.023 & -2.46 & 0.014 & & \\
\hline 25 & 9 & 55 & ALAUNCHES_GE_12 & -0.099 & 0.035 & -2.80 & 0.005 & & \\
\hline 26 & 9 & 5ל & $\Delta$ CLASSES_0_11 & 0.035 & 0.027 & 1.33 & 0.184 & & \\
\hline 27 & & & $\Delta$ CLASSES_GE_12 & 0.070 & 0.050 & 1.42 & 0.156 & & \\
\hline
\end{tabular}




\section{Table 3}

Calculation of the number of life-years saved (i.e., the reduction in years of life lost) before ages 85, 70, and 55 in 2013 by new drugs launched after 1981

\begin{tabular}{|c|c|c|c|c|c|c|c|c|c|c|c|}
\hline & & & & & & & & & \multicolumn{3}{|c|}{ Years of life lost } \\
\hline row & $\begin{array}{l}\text { YLL } \\
\text { age }\end{array}$ & $\begin{array}{l}\text { Param } \\
\text { eter }\end{array}$ & variable & $\begin{array}{l}\text { Parameter } \\
\text { Estimate }\end{array}$ & $\begin{array}{c}\text { wtd. } \\
\text { mean(varia } \\
\text { ble) }\end{array}$ & \multicolumn{2}{|c|}{$\begin{array}{c}\text { estimate * weighted } \\
\text { mean }\end{array}$} & $\begin{array}{c}\text { estimated } \\
\text { ratio of YLL in } \\
\text { absence of } \\
\text { new drugs to } \\
\text { actual YLL = } 1 \\
/ \exp (\Phi)\end{array}$ & actual YLL & $\begin{array}{l}\text { estimated } \\
\text { YLL, in } \\
\text { absence of } \\
\text { post-1981 } \\
\text { new drug } \\
\text { launches }\end{array}$ & $\begin{array}{c}\text { number of } \\
\text { life-years } \\
\text { gained in } \\
2013 \text { from } \\
\text { post-1981 } \\
\text { new drug } \\
\text { launches } \\
\end{array}$ \\
\hline 1 & \multirow{3}{*}{85} & $\beta_{0-11}$ & LAUNCHES_0_11 & -0.031 & 5.2 & & -0.159 & \multirow{3}{*}{2.16} & \multirow{3}{*}{$128,128,140$} & \multirow{3}{*}{$276,784,982$} & \multirow{3}{*}{$148,656,842$} \\
\hline 2 & & $\beta_{12+}$ & LAUNCHES_GE_12 & -0.057 & 10.8 & & -0.611 & & & & \\
\hline 3 & & & & & & $\operatorname{sum}(\Phi)$ : & -0.770 & & & & \\
\hline & & & & & & & & & & & \\
\hline 4 & \multirow{3}{*}{70} & $\beta_{0-11}$ & LAUNCHES_0_11 & -0.036 & 5.1 & & -0.184 & \multirow{3}{*}{2.45} & \multirow{3}{*}{$56,931,332$} & \multirow{3}{*}{$139,553,867$} & \multirow{3}{*}{$82,622,535$} \\
\hline 5 & & $\beta_{12+}$ & LAUNCHES_GE_12 & -0.068 & 10.5 & & -0.712 & & & & \\
\hline 6 & & & & & & $\operatorname{sum}(\Phi)$ : & -0.897 & & & & \\
\hline & & & & & & & & & & & \\
\hline 7 & \multirow{3}{*}{55} & $\beta_{0-11}$ & LAUNCHES_0_11 & -0.044 & 5.0 & & -0.219 & \multirow{3}{*}{2.83} & \multirow{3}{*}{$24,494,810$} & \multirow{3}{*}{$69,429,796$} & \multirow{3}{*}{$44,934,986$} \\
\hline 8 & & $\beta_{12+}$ & LAUNCHES_GE_12 & -0.076 & 10.8 & & -0.822 & & & & \\
\hline 9 & & & & & & $\operatorname{sum}(\Phi)$ : & -1.042 & & & & \\
\hline
\end{tabular}


Table 4

Prescription drug expenditure (millions of USD), by country

\begin{tabular}{|c|c|c|c|}
\hline country & $\begin{array}{l}2013 \text { expenditure on } \\
\text { drugs launched after } \\
1981 \text { (source: IQVIA } \\
\text { MIDAS database) }\end{array}$ & $\begin{array}{c}2013 \text { expenditure, total } \\
\text { (source: IQVIA MIDAS } \\
\text { database) }\end{array}$ & $\begin{array}{c}2014 \text { expenditure, total (source: } \\
\text { International Federation of } \\
\text { Pharmaceutical Manufacturers } \\
\text { \& Associations (2017)) }\end{array}$ \\
\hline Australia & $\$ 5,280$ & $\$ 10,516$ & $\$ 12,150$ \\
\hline Austria & $\$ 2,160$ & $\$ 3,942$ & $\$ 8,100$ \\
\hline Belgium & $\$ 3,006$ & $\$ 5,451$ & $\$ 7,730$ \\
\hline Brazil & $\$ 7,391$ & $\$ 20,624$ & $\$ 26,350$ \\
\hline Canada & $\$ 9,865$ & $\$ 17,665$ & $\$ 21,830$ \\
\hline Chile & $\$ 320$ & $\$ 1,323$ & $\$ 3,470$ \\
\hline Colombia & $\$ 226$ & $\$ 1,278$ & $\$ 4,320$ \\
\hline Ecuador & $\$ 259$ & $\$ 1,040$ & $\$ 1,500$ \\
\hline Finland & $\$ 1,304$ & $\$ 2,453$ & $\$ 3,780$ \\
\hline France & $\$ 17,317$ & $\$ 34,706$ & $\$ 44,700$ \\
\hline Germany & $\$ 22,104$ & $\$ 42,051$ & $\$ 68,860$ \\
\hline Ireland & $\$ 1,392$ & $\$ 2,223$ & $\$ 3,160$ \\
\hline Italy & $\$ 13,693$ & $\$ 25,750$ & $\$ 35,330$ \\
\hline Japan & $\$ 40,806$ & $\$ 75,929$ & $\$ 106,140$ \\
\hline Mexico & $\$ 2,345$ & $\$ 6,489$ & $\$ 12,960$ \\
\hline Portugal & $\$ 1,084$ & $\$ 3,512$ & $\$ 4,550$ \\
\hline Singapore & $\$ 365$ & $\$ 736$ & $\$ 820$ \\
\hline Spain & $\$ 10,766$ & $\$ 19,013$ & $\$ 32,780$ \\
\hline Sweden & $\$ 1,779$ & $\$ 3,691$ & $\$ 5,490$ \\
\hline Switzerland & $\$ 2,820$ & $\$ 5,274$ & $\$ 7,710$ \\
\hline United Kingdom & $\$ 10,037$ & $\$ 19,427$ & $\$ 50,140$ \\
\hline United States & $\$ 191,558$ & $\$ 335,030$ & $\$ 316,340$ \\
\hline Total & $\$ 345,879$ & $\$ 638,120$ & $\$ 778,210$ \\
\hline
\end{tabular}


Appendix Table 1

Complete estimates of model 1 in Table 2

\begin{tabular}{|c|c|c|c|c|}
\hline Parameter & Estimate & Std. Err. & $\mathrm{Z}$ & $\operatorname{Pr}>|\mathrm{Z}|$ \\
\hline$\triangle$ LAUNCHES_0_11 & -0.031 & 0.008 & -3.79 & 0.0001 \\
\hline ALAUNCHES_GE_12 & -0.057 & 0.013 & -4.46 & $<.0001$ \\
\hline Argentina & 0.036 & 0.056 & 0.64 & 0.5225 \\
\hline Australia & -0.188 & 0.073 & -2.58 & 0.0099 \\
\hline Austria & -0.162 & 0.077 & -2.10 & 0.0358 \\
\hline Belgium & -0.142 & 0.080 & -1.77 & 0.076 \\
\hline Brazil & 0.006 & 0.038 & 0.16 & 0.8743 \\
\hline Canada & -0.133 & 0.059 & -2.25 & 0.0247 \\
\hline Chile & -0.053 & 0.066 & -0.80 & 0.4218 \\
\hline Colombia & -0.192 & 0.050 & -3.87 & 0.0001 \\
\hline Denmark & -0.235 & 0.079 & -2.98 & 0.0029 \\
\hline Ecuador & -0.323 & 0.086 & -3.77 & 0.0002 \\
\hline Finland & -0.101 & 0.102 & -0.99 & 0.3224 \\
\hline France & -0.164 & 0.072 & -2.29 & 0.022 \\
\hline Germany & -0.056 & 0.074 & -0.75 & 0.4539 \\
\hline Greece & -0.045 & 0.056 & -0.81 & 0.4159 \\
\hline Israel & -0.452 & 0.102 & -4.44 & $<.0001$ \\
\hline Italy & -0.184 & 0.056 & -3.28 & 0.001 \\
\hline Japan & -0.129 & 0.065 & -1.99 & 0.0464 \\
\hline Mexico & 0.061 & 0.064 & 0.94 & 0.3475 \\
\hline Netherlands & -0.254 & 0.098 & -2.59 & 0.0095 \\
\hline Portugal & -0.295 & 0.094 & -3.14 & 0.0017 \\
\hline Singapore & -0.397 & 0.080 & -4.94 & $<.0001$ \\
\hline Spain & -0.188 & 0.071 & -2.66 & 0.0079 \\
\hline Sweden & -0.156 & 0.097 & -1.61 & 0.1072 \\
\hline Switzerland & -0.228 & 0.066 & -3.44 & 0.0006 \\
\hline United Kingdom & -0.151 & 0.093 & -1.62 & 0.1046 \\
\hline United States & -0.036 & 0.064 & -0.56 & 0.5728 \\
\hline Venezuela & 0.000 & 0.000 & & \\
\hline 30 Tuberculosis & -1.788 & 0.090 & -19.90 & $<.0001$ \\
\hline 70 Gonorrhoea & -2.495 & 0.049 & -51.22 & $<.0001$ \\
\hline 100 HIVIAIDS & -0.882 & 0.103 & -8.57 & $<.0001$ \\
\hline 110 Diarrhoeal diseases & -1.776 & 0.079 & -22.50 & $<.0001$ \\
\hline 170 Meningitis & -1.763 & 0.059 & -30.05 & $<.0001$ \\
\hline 220 Malaria & -2.901 & 0.092 & -31.51 & $<.0001$ \\
\hline 390 Lower respiratory infections & -0.677 & 0.124 & -5.44 & $<.0001$ \\
\hline 400 Upper respiratory infections & -1.073 & 0.072 & -14.98 & $<.0001$ \\
\hline 410 Otitis media & -1.804 & 0.052 & -34.86 & $<.0001$ \\
\hline 420 Maternal conditions & -1.129 & 0.080 & -14.06 & $<.0001$ \\
\hline 620 Mouth and oropharynx cancers & -1.146 & 0.059 & -19.33 & $<.0001$ \\
\hline 630 Oesophagus cancer & -1.148 & 0.053 & -21.76 & $<.0001$ \\
\hline 640 Stomach cancer & -1.268 & 0.043 & -29.40 & $<.0001$ \\
\hline 650 Colon and rectum cancers & -0.939 & 0.049 & -19.02 & $<.0001$ \\
\hline 660 Liver cancer & -1.114 & 0.058 & -19.18 & $<.0001$ \\
\hline 670 Pancreas cancer & -0.780 & 0.037 & -20.91 & $<.0001$ \\
\hline 680 Trachea, bronchus, lung cancers & -0.898 & 0.027 & -33.42 & $<.0001$ \\
\hline 691 Malignant skin melanoma & -0.996 & 0.061 & -16.36 & $<.0001$ \\
\hline 692 Non-melanoma skin cancer & -0.996 & 0.066 & -15.09 & $<.0001$ \\
\hline 700 Breast cancer & -0.675 & 0.070 & -9.70 & $<.0001$ \\
\hline 710 Cervix uteri cancer & -1.231 & 0.072 & -17.12 & $<.0001$ \\
\hline 730 Ovary cancer & -1.035 & 0.027 & -38.71 & $<.0001$ \\
\hline 740 Prostate cancer & -1.038 & 0.032 & -32.78 & $<.0001$ \\
\hline 745 Kidney cancer & -1.081 & 0.066 & -16.46 & $<.0001$ \\
\hline
\end{tabular}


Appendix Table 1

Complete estimates of model 1 in Table 2

\begin{tabular}{|c|c|c|c|c|}
\hline Parameter & Estimate & Std. Err. & $\mathbf{Z}$ & $\operatorname{Pr}>|\mathrm{Z}|$ \\
\hline 750 Bladder cancer & -1.149 & 0.060 & -19.25 & $<.0001$ \\
\hline 751 Brain and nervous system cancers & -0.999 & 0.062 & -16.04 & $<.0001$ \\
\hline 752 Gallbladder and biliary tract cancer & -1.330 & 0.066 & -20.05 & $<.0001$ \\
\hline 754 Thyroid cancer & -1.102 & 0.073 & -15.19 & $<.0001$ \\
\hline 755 Mesothelioma & -0.836 & 0.058 & -14.41 & $<.0001$ \\
\hline 761 Hodgkin lymphoma & -1.358 & 0.075 & -18.15 & $<.0001$ \\
\hline 762 Non-Hodgkin lymphoma & -1.071 & 0.056 & -19.07 & $<.0001$ \\
\hline 763 Multiple myeloma & -1.078 & 0.059 & -18.35 & $<.0001$ \\
\hline 770 Leukaemia & -0.798 & 0.057 & -14.10 & $<.0001$ \\
\hline 800 Diabetes mellitus & -0.361 & 0.125 & -2.88 & 0.0039 \\
\hline 830 Depressive disorders & -0.245 & 0.043 & -5.76 & $<.0001$ \\
\hline 840 Bipolar disorder & -0.300 & 0.033 & -9.23 & $<.0001$ \\
\hline 850 Schizophrenia & -0.470 & 0.038 & -12.23 & $<.0001$ \\
\hline 860 Alcohol use disorders & -1.209 & 0.073 & -16.58 & $<.0001$ \\
\hline 950 Alzheimer disease and other dementias & -0.536 & 0.060 & -8.96 & $<.0001$ \\
\hline 960 Parkinson disease & -0.623 & 0.015 & -42.23 & $<.0001$ \\
\hline 980 Multiple sclerosis & -0.761 & 0.023 & -32.72 & $<.0001$ \\
\hline 990 Migraine & 0.000 & 0.000 & & \\
\hline 1030 Glaucoma & -0.493 & 0.043 & -11.52 & $<.0001$ \\
\hline 1120 Hypertensive heart disease & -0.299 & 0.156 & -1.91 & 0.0557 \\
\hline 1130 Ischaemic heart disease & -0.948 & 0.088 & -10.80 & $<.0001$ \\
\hline 1140 Stroke & -1.341 & 0.034 & -39.14 & $<.0001$ \\
\hline 1150 Cardiomyopathy, myocarditis, endocarditis & -1.285 & 0.063 & -20.41 & $<.0001$ \\
\hline 1160 Other circulatory diseases & -0.360 & 0.170 & -2.12 & 0.0338 \\
\hline 1180 Chronic obstructive pulmonary disease & -0.796 & 0.049 & -16.41 & $<.0001$ \\
\hline 1190 Asthma & -1.544 & 0.043 & -35.56 & $<.0001$ \\
\hline 1200 Other respiratory diseases & -0.713 & 0.087 & -8.23 & $<.0001$ \\
\hline 1220 Peptic ulcer disease & -1.465 & 0.032 & -45.77 & $<.0001$ \\
\hline 1230 Cirrhosis of the liver & -1.166 & 0.070 & -16.70 & $<.0001$ \\
\hline 1244 Inflammatory bowel disease & -1.312 & 0.058 & -22.66 & $<.0001$ \\
\hline 1248 Pancreatitis & -1.171 & 0.072 & -16.39 & $<.0001$ \\
\hline 1250 Other digestive diseases & -0.718 & 0.055 & -13.14 & $<.0001$ \\
\hline 1270 Kidney diseases & -0.701 & 0.073 & -9.56 & $<.0001$ \\
\hline 1280 Benign prostatic hyperplasia & -1.171 & 0.046 & -25.28 & $<.0001$ \\
\hline 1300 Other urinary diseases & -0.147 & 0.126 & -1.17 & 0.2433 \\
\hline 1330 Skin diseases & 0.284 & 0.233 & 1.22 & 0.2232 \\
\hline 1350 Rheumatoid arthritis & -0.939 & 0.050 & -18.79 & $<.0001$ \\
\hline 1360 Osteoarthritis & -1.124 & 0.030 & -37.14 & $<.0001$ \\
\hline 1370 Gout & -1.056 & 0.082 & -12.92 & $<.0001$ \\
\hline 1380 Back and neck pain & -0.282 & 0.029 & -9.89 & $<.0001$ \\
\hline 1390 Other musculoskeletal disorders & -0.351 & 0.100 & -3.50 & 0.0005 \\
\hline 1502 Other oral disorders & -0.929 & 0.074 & -12.56 & $<.0001$ \\
\hline Intercept & 1.120 & 0.095 & 11.78 & $<.0001$ \\
\hline
\end{tabular}

\begin{tabular}{|c|c|c|c|c|}
\hline \multicolumn{5}{|l|}{ Contrast Estimate Results } \\
\hline \multirow[t]{2}{*}{ Label } & Mean Estimate & \multicolumn{2}{|c|}{ Mean } & \multirow[t]{2}{*}{ Alpha } \\
\hline & & \multicolumn{2}{|c|}{ Confidence Limits } & \\
\hline \multirow[t]{5}{*}{$\Delta$ LAUNCHES_0_11- $\Delta$ LAUNCHES_GE_12 } & 0.026 & 0.006 & 0.05 & 0.05 \\
\hline & \multirow{2}{*}{\multicolumn{2}{|c|}{ L'Beta }} & \multirow{3}{*}{ Chi-Square } & \\
\hline & & & & Pr $>$ ChiS \\
\hline & \multicolumn{2}{|c|}{ Confidence Limits } & & $\mathrm{q}$ \\
\hline & 0.006 & 0.047 & 6.27 & 0.0123 \\
\hline
\end{tabular}

